\title{
Analysis of Factors Influencing Choice of Institution for Professional Development: A Case Study of Post- Graduate Students' Perceptions at the Catholic University of Eastern Africa in Kenya
}

\author{
Agnes K. Kalenywa \\ School of Education \\ Mount Kenya University, Kenya \\ Wycliffe Amukowa \\ School of Education \\ Mount Kenya University, Kenya \\ Email:kwamukowa@yahoo.com
}

Doi:10.5901/ajis.2013.v2n2p379

\begin{abstract}
Universities have play key roles in development human resources necessary for the growth of the institutions of the society, be it economic, political or social. To this regard university education has been regarded as the most important cycle in the education system. This explains the rapid expansion of university education in Kenya both in the public and private sector. Postgraduate education has become more marketable than ever before. This is because it provides candidates with specialized skills and competencies, paving way for promotion and widens career choices. Students seeking postgraduate studies apply to institutions of their choice. This paper is intrigued by one major issue: what makes a student to choose one university and not the other? It is in attempt to unravel the issue of choosing universities that this paper endeavours a finding with particular reference to The Catholic University of Eastern Africa.
\end{abstract}

\section{Background}

Lifelong education is a key concept in current thinking about education and training worldwide. Learning takes place throughout the life of an individual and may take place in the formal, informal and nonformal systems (Hinzen, 2000:266). Learning is an important aspect of the peoples lives throughout the world and may take place through institutions such as workshops, work places, community based locations, libraries, and trade unions.

Lifelong education maintains professionals' currency, fulfilment as individual citizens and provides an internationally competitive work force and enrichment of society. One central purpose of continuing professional education is to bring practicing professionals in contact with new knowledge and ideas. According to Eraut (2006), the professional requirement is defined in terms of satisfactory completion of a minimum period of practice in an approved work setting, including a minimum period of practice in number and range of professional tasks, often supplemented by further examinations, written or oral and evidence in form of reports and logbooks.

Kydd, Crawford and Riches (1998) argue that increasingly professional development is being recognized as crucial, not only to the individual but also to the promotion of an effective organization. Professionals are generally being challenged on different fronts. According to International Labour Organization. (2000) professionals of the future need to be creative, able to reason and capable of independent decisions, solving problems and finding information. They should possess characteristics such as capacity to work independently and with others, confidence to make decision, willingness and ability to continue learning.

There is need for elastic views of postgraduate education with undergraduate developing stronger expectations and skills for continued learning. The world is in need of more and better professionals who require a combination of certain basic knowledge and skills. Some of these knowledge and skills include: computing and communication skills and some work place competencies such as being able to manage resources including money, time, deal with technology and equipment, understand systems and demonstrate work related inter-personal skills. 
Professionals continually learn on the job, because their work entails engagement in a succession of cases, problems or projects, about which they have to learn. In this case, specific learning, however, may not contribute a great deal to their general professional knowledge base unless the case is regarded as special rather than routine (Eruat, 2006).

Any framework for promoting and facilitating professional learning will have to take the following factors into account: One; an appropriate combination of learning settings i.e. on the job, near the job, home, library etc; two, time for study, consultation and reflection; three, the availability of suitable learning resources; four, people who are prepared (i.e. both willing and able) to give appropriate support; and five, the learner's own capacity to learn and take advantage of the available opportunity (Eruat, 2006).

The public expects that a qualified professional will be competent in the discharge of normal duties and tasks. According to Tuisman (1995) life long learning degrees and certificates should not be looked upon as an end result of an educational career but rather as steps in a process of lifelong education and personal development across the lifespan of all individuals. Through lifelong education an individual is able to improve his/her, academic and professional qualification, which makes him/her fit in the global network of changes.

For professionals, there is an increasing global connectedness between many societies and economies. All these changes call for people who are adaptable, responsive and capable of continuing life long learning. Therefore globalization of economies, the advent of knowledge based societies and political breakthrough in the direction of democratic forms of government can be forces for positive change because they have the potential to bring the members of the world community together in order to make them aware of each others' needs. This is important to a professional in that he/she will be able to show the interdependence of different regions of the world and the need for international understanding of each other. This is significant because what happens in one region of the world will have an impact on another, and also because of the globally recognized need for mutual co-operation among peoples of different regions and professions in creating a better world.

As Meissner (1995) notes, education has meaning only if it unites the unchangeable in man with the transitory to enable him to react to challenges of his/her day and age in a worthy way. Some of these challenges include HIVIAIDS, drug abuse, environmental degradation and stress in the work place among others. Lifelong education is necessary in this regard because the human person is involved in hazardous enterprises and must put up with the dilemmas of his/her life conceding in equal measures both successes and failures. In addition, education has the duty to prepare the citizens of today to live and work in the world of tomorrow that is continuously changing (Power, 1993).

On the same note, many professionals seek lifelong education for economic or monetary motives such as salary increment upward mobility in their places of work, and/or retention of ones position. Others will seek lifelong education for career development. Lifelong education plus the skills and competencies it embodies are acquired in institutions of higher learning. In Kenya there are seven public and about twenty one private universities from which graduate students seek continuing education.

\subsection{About Catholic University of Eastern Africa}

Catholic University of Eastern Africa is a private University that was established in 1985 by the Episcopal Conferences of eight Eastern African countries namely, Eritrea, Ethiopia, Kenya, Malawi, Sudan, Tanzania, Uganda, and Zambia which form (Association of Member Episcopal Conference of Eastern Africa (AMECEA).

The mission statement of the Catholic University describes it as an instrument of liberation and transformation of people's in their social, cultural, political, economic and religious dimensions. It is an academic agent for creating knowledge and producing graduates who are competent leaders for the church and society. CUEA is founded on the philosophy of the Catholic Higher Education that stresses free search for the truth about nature, humanity and God. It promotes the exploration of every path of knowledge and conscious of being preceded by him who is the Way, the Truth and the Life. The university's conviction is that the spirit of the Lord Jesus Christ enables human beings through the development of their intelligence and talents to find meaning to life.

Inspired by the words of Jesus in John 17:7, "Consecrate them in Truth" the university seeks to promote scientific research, quality teaching and community service for the purpose of enhancing Christian loving. There are six faculties in the University, namely, Commerce, Arts and Social Sciences, Education, Law, Science and Theology, each of which has both undergraduate and post graduate programmes. 
The postgraduate programmes are specifically tailored to provide the students with relevant attitudes, skills, knowledge and competences that equip them for service in the society. Over the years since her establishment CUEA has attracted an ever-growing population of postgraduate students from Eastern African countries and beyond. It is imperative to investigate the factors that influence the choice of CUEA as preferred institution for profession development among postgraduate student. It is also important to assess their perceptions in regard to the academic programmes, social relations and monetary implications thereof.

\subsection{Research Questions}

This study was guided by the following research questions:

1. What factors influence postgraduate students to pursue lifelong education?

2. What factors determine one's choice of institution for postgraduate education in view of professional development?

3. What are the perceptions of postgraduate students of Catholic University of Eastern Africa on the quality of educational programmes and relevance on their respective professions?

4. Is there a relationship between students' desire for postgraduate studies and selected demographic characteristics?

5. Is there a relationship between students' choice of CUEA and selected demographic characteristics?

\subsection{Hypotheses}

The study was guided by the following four hypotheses.

1. There is no significant difference in the mean desire for postgraduate studies score of students when categorised by sex.

2. There is no significant difference in the mean desire for postgraduate studies scores of students when categorised by faculty.

3. There is no significant difference in the mean choice of CUEA score of students when categorised by sex.

4. There is no significant difference in the mean choice of CUEA scores of students when categorised by faculty.

\subsection{Significance of the Study}

The general purpose of this work was to establish and analyze the perceptions of post graduate students of CUEA in regard to the quality of the academic programmes, marketability and relevance of the programmes and the impact of these programmes to their respective professions. The study is likely to assist policy makers and administrators at CUEA in enhancing and upgrading educational programmes and the social environment of the institution in line with the aspirations of the customers.

\subsection{Scope and Delimitations of the Study}

The study is delimited to the postgraduate students at the Catholic University of Eastern Africa. This scope was chosen because of two main reasons. First, CUEA is a private institution where tuition and academic fees are relatively high than they are in public universities. Secondly, the institution is far away from the city centre compared to other universities which have town campuses. Despite these there are many students seeking postgraduate studies in the institution every year.

\subsection{Theoretical Framework}

This study employed two theoretical frameworks, namely: Maslow's theory of Hierarchy of Needs and the Human Capital Theory as propagated by Theodore Shultz. Let us now briefly discuss each of these two theories.

Maslow's theory of Hierarchy of Needs was developed in the 1940-50s by Abraham Maslow (1908-1970) a native of New York. It states that human beings are driven to act by a variety of needs, and that these needs are hierarchically structured, from the lowest to the highest. People ordinarily fulfil the lower needs before they aspire for the higher ones. 
Maslow's Hierarchy of Needs is predetermined in order of importance. It is often depicted as a pyramid consisting of five levels; the first lower level is associated with physiological needs, while the top levels are termed as growth needs with psychological needs. Deficiency must be met first. Once these are met, seeking to needs drives personal growth. The higher needs in this Hierarchy only come into focus when the lower needs in the pyramid are not met. Once an individual has moved up in the next level, needs in the lower level will no longer be prioritized. If a lower set of needs is not being met, the individual will temporarily re-prioritize these needs by focusing attention on the unfulfilled needs, but will not permanently regress to the lower level.

The theory remains valid today for understanding human motivation, management training and personal development. Indeed, Maslow's ideas surrounding the Hierarchy of Needs concerning the desires and responsibilities of employees to fulfil their own unique potentials (self-actualization) are today more relevant than ever.

This theory was found relevant to the subject under investigation in that post graduate students are presumed to be in search of, among other things, certain values such as self-actualization which they believe can be achieved through professional development. Lifelong education is therefore here understood to be a key avenue through which the candidates seek to pursue the higher goals that range from monetary gains to desire for promotion at workplace, from personal development to career development and finally, from competence enhancement to marketability in the job market. However, the drives for professional development should not be limited to the aforesaid; rather they should go a notch higher (in line with Maslow's theory) into seeking self esteem and self actualization. The following schematic diagramme illustrates the hierarchy of needs as illustrated by Maslow.

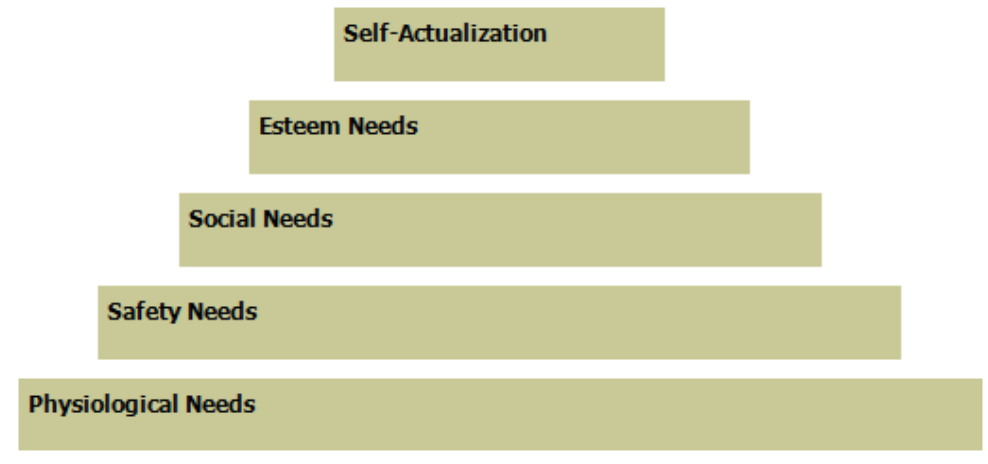

Fig I A pyramidal schematic diagram illustrating Maslow's hierarchy of needs

The human capital theory was propagated by Theodore Schultz, G.S Becker, M. Spence and L. Thurow. It suggests that education and training raise the productivity of workers by imparting useful knowledge and skills, hence raising workers future income by increasing their lifetime earnings. While distinguishing between general and specific education human capital theory holds that formal schooling is a crucial factor in explaining variations of salary and wages. Formal education has expanded rapidly in many countries just as accumulation of human capital in form of on-the-job training and other modes of learning for working adults have been on the rise. Formal education is seen as a viable option for performance enhancement and raising wages. This underscores the fact that further education is an investment at some relatively riskless rate of return. Thus a person is ready to spend money (in further education) to acquire knowledge and skills that would lead to enhancement of his/her performance and better remunerations. However some forms of return are not monetary in nature.

While Becker (1964) suggests that education and training raise the productivity of workers by imparting useful knowledge and skills others provide different explanations as to how education is related to worker productivity. One is based on the argument that the earnings of the educated workers simply reflect their superior ability acquired during the process of education rather than through skills and knowledge.

Spence (1973) argues that education is used as a market signal to indicate the potential productivity of workers. Thurow (1975) maintains that productivity is largely a characteristic of jobs rather than workers: employers use education credentials to select workers because better educated workers can be trained for specific jobs more quickly and at a lower cost than their less educated peers. 
Schultz (1975) on the other hand maintains that education enhances an individual's ability to successfully deal with equilibria in changing economic conditions. Such ability includes that of perceiving a given disequilibrium, analysing information and reallocating resources to act. He promulgated the idea of educational capital as an offshoot of the concept of human capital relating specifically to the investment made in education. Schultz views education as an investment and regards the consequences of education a form of capital. He regards education as a 'human capital' because education becomes part of the person receiving it. It becomes an integral part of the person and as such cannot be bought, sold or treated as a property.

Education is a form of capital since it renders a productive service of value to the economy. This means that national as well as individual incomes are positively affected by the additions (mainly through education) to the stock of this form of capital. This is mainly so because the knowledge, skills and competences gained through education and training can alter the wages individuals receive.

This theory was found relevant to this study primarily due to its emphasis on the correlation between specific education and better remuneration. In this study specific education is equivalent to postgraduate education which graduate students pursue for professional development. However, as noted in the findings of the study, other factors other than professional development and competence enhancement motivate graduate students to pursue postgraduate studies. Some of these factors are extrinsic and economic in nature such as desire for salary increment, job retention and prospects for promotion.

This study, as the findings indicate in chapter four, noted that there are both intrinsic and extrinsic factors that influence the desire for postgraduate education. Maslow's theory of hierarchy of needs mainly caters for the intrinsic factors such as self-actualization, personal growth, self-esteem, to be like one's peers among others. On the other hand the Human Capital theory explains the extrinsic or monetary factors that influence pursuit of postgraduate education. The basic factors among such are competence enhancement, possibility of promotion and salary increment. The two theories (Hierarchy of Needs and Human Capital theory) complement each other in this study by propounding on both the intrinsic and extrinsic factors that influence the pursuit of postgraduate education.

\subsection{Conceptual Framework}

The conceptual framework employed in the study provides the basis for exploring aspects necessary in achieving professional development through lifelong education. In this study certain factors have been identified as key to enhancing professional development through lifelong education, particularly post graduate studies. These factors include community input, enabling conditions, individual factors and professional challenges.

Community input refers to those expectations and plans that the Kenyan Society holds about its professionals in view of maximum individual development and productivity in the general life of the nation. For instance seven (7) public universities and twelve (12) private universities in Kenya provide post graduate academic courses and programmes aimed at careers and professional development. As such facilities and equipment for professional development are available locally and a variety of learning modes such as regular, evening classes, weekend programmes, school focused, open learning, distance learning and electronic learning. These varieties cater for the needs of various professionals throughout who would want to advance their careers.

Certain factors are expected to motivate one to pursue post graduate studies. These range from a desire for selfactualization to a need for personal growth, from desire for monetary rewards to mobility in the professional ladder and from competence enhancement to sharpening of skills to deal with emerging issues at the work place.

Apart from the individual and personal factors, there are also professional challenges and requirements that may motivate one to pursue professional development, these include the need to know and employ a variety of modern professional strategies for maximum effect and productivity with the least minimum effort. On the same note professions require their professionals to constantly upgrade their knowledge and kills in regard to certain areas in the given careers. This even made more urgent by emerging issues such as HIV and AIDS, the current economic meltdown, ICT, conflict management, stress management at the work place and the need for effective communication at the work place.

For one to choose one institution over another a candidate is influence by several factors. First among them is the affordability of tuition fees. Secondly is the convenience of the location of the institution in terms of accessibility. Thirdly is the attractiveness and marketability of the post graduate programme that one wishes to pursue. Fourth is the quality of the degrees offered in regard to job opportunities. Fifth is the availability of the learning resources and lastly, the availability and motivation of lecturers. 
When the above factors have been put into consideration the student makes a choice for a given institution and pursues his/her choice course. In the final analysis several effects are expected of the candidate. These include selfactualization, academic achievement, professional and career development, economic monetary reward, competence enhancement and acquisition of new skills and attitudes necessary in ones profession.

The following schematic diagram summarizes this framework as used in this study.

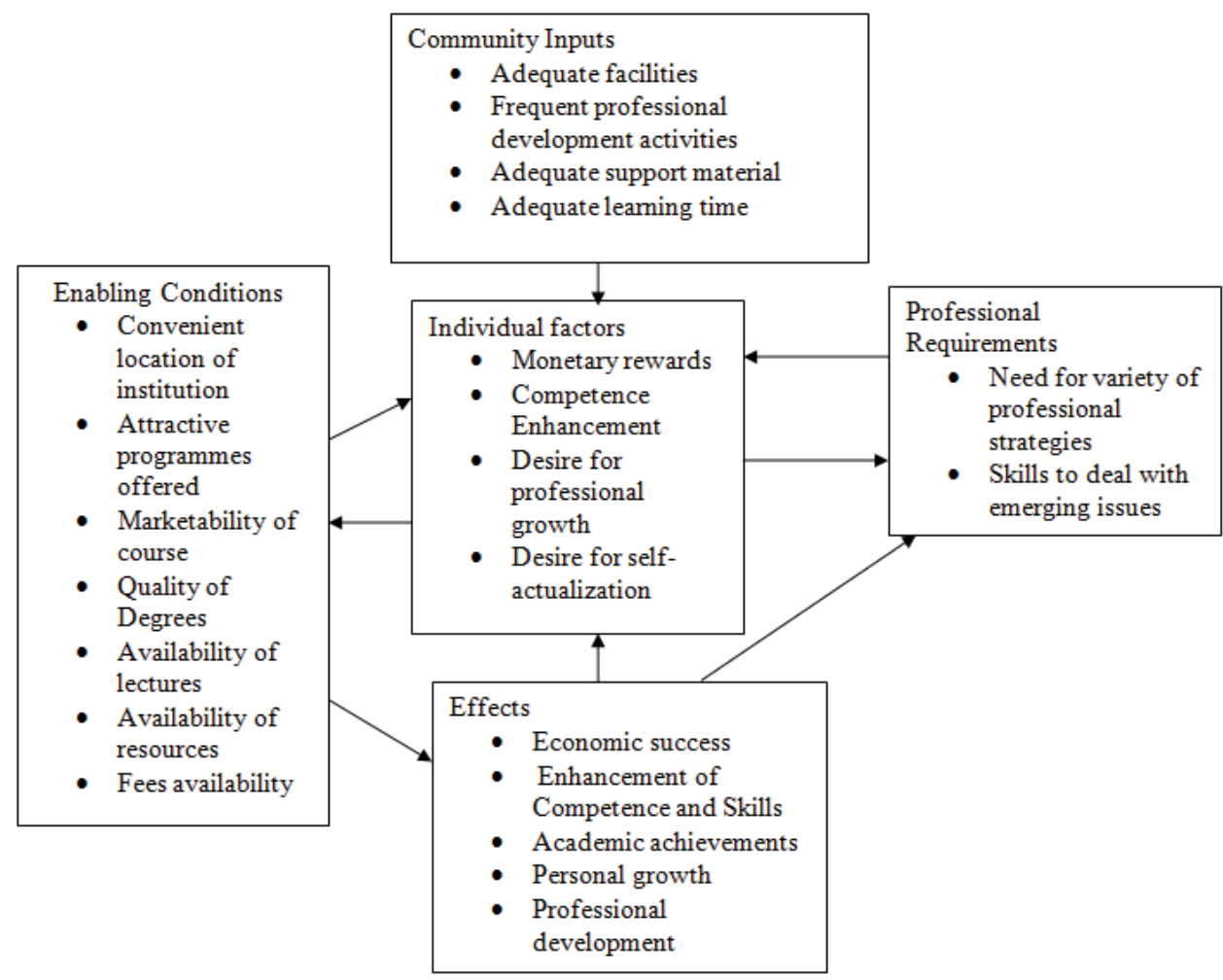

Fig 2: Schematic diagram summarising the conceptual framework employed in the study.

\subsection{Definition of Operational Terms}

Professional Development This refers to those educational courses that offer certification and provide candidates with specialized skills, competencies knowledge and attitudes.

Lifelong education Refers to as continuing education in this work: Refers to any learning that occurs at any stage of one's life and that is directed to improving the quality of life of the individual.

\section{Literature Review}

\subsection{Introduction}

The aim of this chapter is to review recently written literature, surveys and researches on professional development with a view of determining the line this work took and fill the research gaps. This literature review used the following themes.

i) Lifelong development and professional development

ii) Professional development and competence enhancement

iii) Professional development and competitiveness in the job market 


\subsection{Review of Related Theories}

In this section the study offers a review of several empirical studies relevant to the subject under investigation, which have been conducted in the recent past.

\subsubsection{Lifelong education and professional development}

We live at a time when so many changes are taking place particularly in organizations, curricular and educational innovations. Along with the changes, it is important that we should have systematic and relevant data on professional behaviour of employees. This is particularly important taking into account that the quality of production depends mainly on the personal characteristics, academic and professional qualifications and the interaction between the employee and her/his colleagues.

Professional development in principle is supposed to be initiated by the employer. The employer does this after job analysis and after discovering that there are areas, which need attention for the purpose of improving production, job satisfaction, reduced supervision and more security on the job. Ideally it is the employer who is supposed to meet all the expenses and whenever possible give an inducement to the employee.

Kaufmann et al, (1997) made comments about the need for employees to perform "Better! Faster! and Cheaper!" due to the fact that the world is constantly changing. Professionals continually learn from the job, because their work entails engagements in a succession of cases, problems or projects, which they have to learn about. Professional development is essential for every individual whether employed or not. It is vital for every business or organization to increase the knowledge of their employees. They should strive to enhance the quality of performance, to ensure improvement on the personal and professional front.

Professional development is necessary to increase knowledge and skills through certified and consistent education in the profession. A professional development programme boosts the individuals' career through travel, research, workshops and seminars and by working with professionals who are experienced. People take up a professional development course to build up their expertise in teaching, accounting etc. and contribute to organizational development.

Professional development courses are either general or skill based. General professional development caters for general skills, through basic personal education. Skilled development on the other hand deals with current profession, leadership qualities, managerial skills and enhancing a person's productivity. The courses are designed with the intentions of developing a person's level of competence and professionalism. The successful completion of the course opens avenues for unlimited growth following Knowles (1970) as quoted by Carlson who commented on the need for better learning strategies for adult learners due to the rapidity of change.

\subsubsection{Professional development and competence enhancement.}

Continued professional development has been defined by Madden and Mitchell (1993) as maintenance of the knowledge, expertise and competence of professionals throughout their careers according to a plan formulated with regard to the needs of the professionals, the employer, the professions and society. There is a clear indication that the one of the purposes of all continuing professional development is to promote effective performance at work Jones, N, Fear, N. (1994). Recent international discussion concerning continuing professional development also focused their on the needs of the individual professions or the interest of the professional bodies.

In this post industrial era, the world of work is held to be fraught with uncertainty, globalization, deregulation of labour markets, privatizations, technological advances, changing employment patterns, changing organizational forms and structures, demographic and labour markets changes, changing balance of work and non-work life, increased job insecurity and changes in education, Blusten (2006), Collins and Watts (1996), Storey (2000). According to, Mckenzie and Wurzburg (1997), Education systems for Lifelong education are essential if individuals are to remain employed throughout their working lives including to be prepared for trends or changes in labour markets. University graduates are prepared to sustain this employability over their lifetime, in the evolving context of the world of work, is a crucial issue pertaining to employability, and moreover, their lifelong career development. Though according to Mcliveen (2007), there is a degree of scepticism among academicians about the relationship between career developments and exigencies of education and industry. 
Continued professional development seeks enhanced competence, and competence is defined in terms of performance, clearly the concept of continued professional development cannot be divorced from the requirement to ensure that activities, which are undertaken, are consistent with the strategic and operational business plan.

Nevertheless, it would be incorrect to relate competences to performance of a person. In cognitive psychology competence is distinguished from performance, because performance because performance requires action, while a person can be competent to do something without actual doing. This approach is explained by Messick (1984)

Competence refers to what a person knows and can do under ideal circumstances, whereas performance refers to what is actually done under existing circumstances. Competence embraces the structure of knowledge and abilities, whereas performance subsumes as well as the process of accessing and utilizing those structures and a host of affective, motivational, attentional and stylistic factors that influence the ultimate responses, Eraut (2000).

Some educational programs prepare for a specific profession, or a limited set of jobs and occupations. Medicine is an example. Other programmes prepare for a broad range of occupations, such as economics (Borghans \& de Grip, 1999; De Wolf, 2000). And again other programs take positions in between, resulting in differences in the priority for different types of competence. Moreover, priorities may vary when considering competences that are most important for entering the labour market versus those that are important for functioning later in the career. It seems inevitable that choices have to be made about what priorities prevail and why. These choices are more easily made when supported by empirical data about the effects of differential educational achievements of students on their labour market outcomes. And it is exactly here where the data are missing. A considerable lack of empirical evidence seems to exist, especially when it comes to what students actually have learned in education, and the effects of competence development in education on labour market outcomes (see, e.g. Sørensen, 1994; Bills, 2003).

Competence-oriented education emphasizes the integrated nature of what students must learn to be prepared for working life. In fact, current competence-based education integrates features of several other innovations in education (such as self-regulated learning and elements of PBL or project learning), instead of having a unique form or character itself. It merely reflects the overall vision on the objectives of education for these innovations. Advocates argue that the traditional division in separate skills, knowledge and attitudes that students must learn in education is rather artificial. And competence is what in fact has been underlying the separate elements that can be distinguished and measured in the first place (see, e.g. Paulson, 2001). Although more difficult, the measurement of 'competences' instead of separate elements has the advantage that it has more day-to-day reality value. Competence oriented and competence-based education has proven its value, as illustrated by examples worldwide (see, e.g. Boyatzis et al., 1995; Stillman et al., 1997; Schlusmans et al., 1999). How the integrated 'competences' should be assessed in academic education is a matter of ongoing discussion and development (see, e.g. Bers, 2001; Elshout-Mohr et al., 2001, 2002; McMullan et al., 2003).

\subsubsection{Professional development and competitiveness in the job market}

Today's labour conditions have become highly changeable. People often work in several and different work settings over time. Especially the higher educated are expected to create their own career paths, in which personal development and growth in responsibility seem to play an important roll (Hall \& Moss, 1998). Personal growth and development result in a delicate mix of what people have available from innate and their experiences from growing up and being educated. For successful functioning and development afterwards, labour market relevant knowledge and skills, together with personal competencies are seen as vital (Anderson \& Marshall, 1994; Nijhof, 1998).

\subsubsection{The role of academic education for the labour market}

Education plays an important major role in what people learn before entering the labour market. In knowledge society or knowledge economy, higher and academic education is faced with the large responsibility to prepare students for functioning on the labour market in higher level and management positions. Some authors emphasize the crucial role of the so - called 'specific' competences development during education: the professional or field-specific knowledge and skills that are relevant for the type of job for which the educational programme prepares (Boshuizen, 2004). Other authors argue it is most important to pay attention to the so - called generic competencies, skills like the ability to learn and more academically conceptual competence, as well as communication and teamwork skills, Mulders, (1995), Stasz, (1998) and Vermetten, (1999). 
This apparent contradiction may be explained by two factors. On the one hand, educational programs may have different goals regarding the preparation for the labour market. On the other hand, different priorities in education relate to different definitions and classifications of competence and to different operations.

All managers and employees have the right to expect a good salary, a progressive career structure, heightened job satisfaction through better working conditions and a better life balance, in return for increased responsibilities and a commitment to continuous professional development. Continuous professional development enables people to keep their skills marketable when looking for a new job but it is also becoming increasingly important in demonstrating that an individual can continue being effective in an existing role. The benefits of continuing professional development are not only felt when a manager or an employee goes for promotion. Learning agility is one of the core competencies valued by many employers) Williams, C. (2006). Ability to manage own professional growth is recently recognized as a key strength. Indeed, demonstrating the ability to go on learning new skills may increasingly become synonymous with having a job.

By emphasizing generic competences rather than direct subject relevance, it can help to resist creeping vocationalism in terms of course content, and to legitimize the continuing value of traditional academic disciplines, employers tend to be concerned with generic graduate attributes than with subject knowledge (Harvey et al., 1997).

Life long learning is also relevant to what Bridges (1993) terms as transferring of skills: the meta skills ... which enable one to select, adapt, adjust and apply one's other skills to different situations, across different social contexts and perhaps similarly across different cognitive domains. Transfer of skills appears clearly to be enhanced by the use of varied learning contexts as seen in Wolf et al. (1990) this makes it possible to practice the skills in different settings, or at least to see their relevance to those settings. This is the rational of inclusion of work experience within higher education.

\subsection{Review of Related Empirical Studies}

In this sub-section we shall offer a review of several empirical studies, conducted in the last ten years that have been found relevant to the subject under investigation. This review will follow a thematic approach as indicated below.

\subsubsection{Professional Development and Competence Enhancement}

In general professional development is seen as one of the key levers for aligning science instruction. Although there is an increasing consensus as regards what constitutes effective professional development, there is little empirical evidence to support this consensus. A study conducted by Banilower (2007) examines the impact of professional development that is content-based, situated in classroom practice, and sustained over time on teacher attitudes, perceptions of preparedness, and classroom practices. The professional model used in this study differed from previous initiatives in that it targeted all teachers in a jurisdiction and emphasized preparing teachers to implement project-designated instructional materials. Analyses of the data provide confirmation that this model for professional development has an impact on teachers and their classroom practices. In addition, the analyses found that teachers' perception of principal support for "Standards"-based science instruction is an important predictor of these outcomes.

The study concentrated on teachers and this study will involve teachers and other professions.

Another study was conducted by Chivers (2007) on professional development with the aim of determining the ways in which post graduate study in vocational fields supports the development of advanced competence amongst mid-career professionals. The study showed that the main domain where mid-career professionals on post graduate course were most strongly challenged to learn and develop in advanced competences was the meta-competence domain on the Cheetham and Chivers model. The learning areas were assigned to one or more competence development domains. The results demonstrate that the main domain where mid-career professionals on this postgraduate course were most strongly challenged to learn and develop in advanced competences was the meta-competence domain on the Cheetham and Chivers model. Research limitations/implications: The study was limited since it was based on written communications passing between a limited number of students and one tutor on a single postgraduate study programme. This therefore means that there is clearly great scope to extend this form of research given the large number of postgraduate vocational study programmes now undertaken by mid-career professionals. It also implies that tutors need to focus strongly on supporting the very demanding learning leading to the growth of meta-competencies. Given the ready availability of relevant factual information to mid-career professionals in the information age, there is much less need to focus on teaching facts, although supporting the interpretation and application of such factual information by 
students retains great importance. Few other studies which attempt to analyze written communication between tutors and post graduate students on professional courses in terms of how such courses are developing professional competences exist.

A study carried out by Abasov (2007) in Ulianovsk Pedagological University sought to examine the problem of the professional and life self-determination of students enrolled in pedagogical educational institutions, with Ulianovsk Pedagogical University serving as the base. The objectives were the following: the study was aimed at establishing the reason as to why the students in the different stages of their schooling chose the pedagogical profession; to determine whether there was a functional relation between the student's motive for choosing the school teaching profession and his/her orientation toward pedagogical activity; to discern the factors of the teaching and learning process in the institutions that have an influence on shaping attitudes toward the pedagogical profession and to determine the dynamics of the students' professional and life plans. The study found a definite connection between the respondents' social or external motives for choosing the profession and their plans in life. This study will be conducted at CUEA and will seek to establish the perceptions of post graduate students on the choice of institution for professional development.

A paper by Sibbel (2009) argues that higher education should be aligned towards meeting the challenge of global sustainability. The barriers to sustainability are juxtaposed against the resources, responsibilities and potential of higher education. Ideas from several models and from within several disciplines should be included to create a framework through which the challenges can be examined and then translated into learning outcomes, articulated as graduate attributes. Future professionals, involved in managing resources or designing options from which consumers make choices, are in a much better position for influencing how social, cultural and environmental resources are used. To actualize this potential it requires that higher education curricula offer experiences which develop graduate attributes of self-efficacy, capacity for effective advocacy and interdisciplinary cooperation, as well as raise awareness of social and moral responsibilities associated with professional practice. For higher education to contribute towards achieving sustainability, it requires support by the whole institution, and considerable professional development of the staff to help them appreciate how they can lead the next generation to global sustainability. Higher education can also assist in building a sustainable society and focus on how these objectives can be achieved. Considerable research has been dedicated to describing the urgent and inflexible nature of the problems facing the global community and, to some degree, the need for higher education to engage with these problems (Sibbel, 2009).

This particular study sought after professional development and sustainability in the society but this study sought to find out the reasons as to why post graduate student at CUEA chose the institution for their professional development. It would be interested in what the postgraduate students thought about the institution when they chose it for their professional growth.

Institutions of higher learning need effective and efficient methods of professional development for preparing graduate students for the job market. These skills are important both for their pressing roles as employees and for their ultimate roles in the professoriate. An iterative process model from instructional design can function as a cognitive organizational framework for the development of professional teaching proficiency. It facilitates know-how by supporting employees in linking new and existing knowledge about their area and learning in meaningful ways that reflect the cognitive processes of authority in their field of specialization. Thus, it can support both the current and future development of professional expertise and facilitate the application of knowledge in the form of working strategies (Hardre, 2005).

New and important challenges are placed on teacher education by the diversity and intricacy of the post-modern era. The fundamental role that personal dispositions have for professional learning needs to be better understood and acknowledged. Teacher training programmes need to focus more on objectives such as promoting conflict literacy, selfawareness, understanding; leadership and collaborative skills, that is taking into account not only the cognitive but also the social and emotional aspects of human development. In this study, Swedish lecturers' descriptions of what they consider to be competences and qualities necessary for future teachers constitute the starting point for a wider discussion on the decisive role of beliefs and emotions in being and becoming a teacher. Issues raised here should be able to contribute to a better understanding of what it means to be a teacher and, consequently, result in improvements in the planning of teacher training programmes (Malm, 2009).

As novice professionals enter into practice they requires to construct identities that fit into that world; part of the role of professional education is to help novices create these identities. During the transitional time represented by professional education, post graduate students negotiate images of themselves as professionals with the images reflected to them by their programmes. This process of negotiation can be filled up with difficulty, especially when these 
images are in disagreement. Novices should therefore learn to personal identify with the professional role as they familiarize themselves with the new roles, even as they find their way among the different images of professional identity offered by their programmes and practitioners in the field (Ronfeldt, 2008).

The study looked at professionals who are being prepared for the job market but this study will look at professionals who are already in the job market and seeking to advance professionally. What compels these professionals sought to advance professionally and why they chose this (CUEA) particular institution.

Chivers (2006) conducted a study on the work roles and development needs of Vocational Lifelong Education (VLL) professionals in British higher education. The purpose of this study was to investigate the career management and development needs of such university staff. The study employed the survey design. Data were collected from professionals in higher education to establish the position and their future prospects. The findings revealed that experienced VLL staff is being required, in some cases unwillingly, to move away from activities concerned with external training to take on work in areas such as technology transfer and general student recruitment. It was concluded that this development is likely to be to the detriment of VLL provision by universities. The implications of this findings is that VLL staff identify further knowledge of new developments in the field, stronger IT skills, and competence in conducting research as their major development needs.

This study sought data from VLL professionals alone hence source triangulation was not considered. The study was concerned with the work roles and development needs of vocational Lifelong education professionals. The current study however, seeks to explore the factors influencing choice of institution for professional development among postgraduate students at the Catholic University of Eastern Africa.

\subsubsection{Professional Development and Competitiveness in the Job Market}

In the recent past, there has been more and more talk about the fact that the system of professional education has to meet the continually changing need for specialists in the labour market. In the author's view, this is where the setback lies: the labour market requires that education satisfy its social and economic needs with respect to a supplying qualified work force, while the education market satisfies the individual's personal need to obtain an education. And so, it is necessary to examine not only the professional and qualification inequality of the labour market per se, but also to increase a detailed understanding of the transformations that are going on in the system of education as a social institution, transformations that do or do not make it possible to suit the increasingly critical social and individual educational requirements. The author states that, what is important today, is not to master a prestigious profession or even a particular profession that is going to be in demand in the labour market, but rather to accomplish a particular educational and cultural level, to master particular competences in order to be able to contend, so that the worth of the "commodity" will be able to meet the requirements of the "consumer," the labour market, and the employer. Therefore, it is institutions of supplementary professional education that will have to correct the situation of the inequality between the supply and demand of the work force in the labour market, education centers that are engaged not only in training but also retraining and advancing of qualifications, as well as vocational guidance.

Harvey, Sinclair and Dowson (2005) conducted a study that investigated teachers' motivations to undertake professional development, in particular where postgraduate study is involved. Specifically, the study involved the development, design and implementation of a psychometric instrument to measure Christian teachers' professional development motivations. Influential factors identified in the continuing professional education literature, and the motivation psychology literature (specifically from Expectancy-Value and Goal theories), were operationalized in the psychometric survey. The resulting instrument, the EMAPS Scale (Educators' Motivations and Attitudes towards Postgraduate Study) included 18 factors. Results of the study indicate that the subscales (factors) of the EMAPS Scale are substantially reliable (most alpha reliabilities being in excess of .80). Also, Confirmatory Factor Analysis indicates support for the factorial validity of most of the items and factors in the EMAPS Scale (with goodness-of-fit indices meeting criterion values in most cases). However, one section of the EMAPS Scale did not demonstrate substantial validity.

Ackah and Heaton (2004) carried out a study on the reality of "new" careers for men and for women. The study focused on the career paths and career progression of men and women in management occupations. The study set out to explore the extent to which the traditional career has been replaced by the so-called "boundaryless" career. In particular it sought to establish whether such new career patterns have been more readily espoused by women than men. The participants in the research were postgraduate, post-experience students on management courses within the Faculty of Business and Management at the University of Ulster. The findings suggest that both men and women are making 
more frequent job moves than in the past and that the vast majority of both men and women are assuming responsibility for their career development. The study finds a growing similarity in male and female careers but very different perceptions regarding factors influencing career paths and career progression. This has implications for providers of management development and education as it appears that much could be done to convince women they can have control over their own careers.

Sax and Bryant (2006) conducted a study on the impact of college on sex-atypical career choices of men and women. It sought to identify the college environments and experiences associated with changes in sex-atypical career aspirations among men and women. A sample of 17,637 students attending baccalaureate institutions across the country was surveyed upon college entry and again 4 years later. The findings revealed that aspects of the college environment, including the peer culture, faculty interaction, and curriculum, all contribute to shifts to or from nontraditional career choices.

The current study will want find out what is the driving force behind the desire by the post graduate students at CUEA to grow professionally while this study has looked at professional development and the labour market. How the education has to satisfy the labour market needs.

\subsection{Conclusion}

In this chapter literature that was found relevant and related to the topic under study namely, professional development for competence and career, competitiveness in the job market and personal development was reviewed. It was noted that professional development is an essential part of continuous education also known as lifelong education. It does not only improve the individual person who pursues continuous education but enhances productivity and effectiveness within the organization.

Through professional development a professional acquires certain skills, knowledge, habits and attitudes that give him/her an upper edge over his/her colleagues who have not gone through the same course. Consequently to his/her entire professional qualification, a professional who has undertaken a post graduate professional degree will be more marketable in the job market than his/her colleagues who have not. Professional development therefore promotes personal development, professional enhancement and competitiveness in the job market.

\section{Research Design and Methodology}

\subsection{Introduction}

This chapter describes the design and methodology that the researcher used to conduct the study. It also comprises the target population, description of the sample and the sampling procedures. The description of the research instruments and how their validity and reliability was tested, data collection and data analysis procedures were also presented.

\subsection{Research Design}

This study adopted both the quantitative and qualitative paradigms. Specifically, a case study design was used. Case study is a way of organising data for the purpose of viewing social reality. The case study design examines a social unit as a whole. The unit may be a person, family, social group, a social institution or a community. The purpose is to understand the life cycle or an important part of the life cycle of the unit. A single case study emphasises analysis in depth. Case study probes deeply and analyzes interactions between the factors that explain present status or that influence change or growth (Best and Kahn, 2003). The case study design was therefore used because an in-depth study of the factors influencing choice of institution for professional development among postgraduate students in the Catholic University of Eastern Africa.

It helps to explain educational phenomena in terms of conditions or relationships that exists, opinions that are held by professionals, effects that are evident or trends that are developing in the work environment. The aim is to obtain complete and accurate information Selltiz (1976). The researcher used questionnaires, interviews and focus group discussions to collect data from the respondents. 
The survey design was preferred because the researcher was interested in describing the existing phenomenon without any manipulation. This design was also preferred because the findings of the study will be generalised to the whole population.

The study was largely descriptive in that it sought to explain the feelings and perceptions of various respondents in regard to CUEA's position as a university of choice for professional development. The descriptive approach was employed in the present study due to a number of reasons. First, descriptive studies are not limited to one method of data collection. Therefore when collecting data on the determinants and perceptions of lifelong education among post graduate students in CUEA, the use of survey method of data collection will be employed and this will help minimize the shortcomings of one particular method. Information this case questionnaires, interviews and focus group discussions will be utilized to collect information from post graduate student of CUEA.

Secondly, the objectives of this study were to illuminate the understanding of how professionals embrace lifelong education. Apart from engaging in courses geared towards certification, there are other avenues which professionals can utilize to gain new knowledge in the improvement of their work, production and marketability. Thus the descriptive design that the study will utilize has the strength of finding out these new avenues therefore gaining more insight into the context within which, post graduate students of CUEA embrace lifelong education. Though the results of the study cannot be generalized within the national context, they provide important insight of determinants related to professional's lifelong education that can have impact on professional production in the country. This is because some aspects found in CUEA are shared by other universities in Kenya.

Thirdly, the study was interested in examining lifelong education among professionals as a process and not as a final product. This process begins at the undergraduate training of professionals and is expected to continue throughout the professionals' life by enrolling in activities geared towards the improvement of their professions, careers, marketability and updating themselves with new information available through many different channels. Thus understanding what conditions influence professional lifelong education requires research procedures that will enable professionals account for their own present realities. Therefore the descriptive design used in this study had the advantage of using interviews where the informants were allowed to express him/her in a way that their deeper attitudes and perceptions on issues of lifelong education emerged. Lastly, the underlying research approach that guided the fieldwork and data analysis for the study would be quantitative in orientation. However some qualitative data was utilized for the purpose of clarification and strengthening of quantitative data.

\subsection{Target Population}

The target population in this study were the deans of faculties, heads of postgraduate departments in various faculties and the postgraduate students. The deans of faculties and heads of departments were part of this study because they gave information on the factors that influence graduate students to pursue continuing education as well as factors that attract the graduate students to pursue postgraduate studies in the Catholic University of Eastern Africa. They were also expected to give insights into the nature and design of academic programmes offered at CUEA and the envisaged products in terms of student competencies and qualifications.

The postgraduate students took part in this study because they gave valuable information on the factors that influence them to pursue continuing education, what they considered when choosing The Catholic University for postgraduate education as well as their perceptions on the quality of educational programmes offered at CUEA as well as their marketability, relevance and impact on their respective professions.

\subsection{Description of Sample and Sampling Procedures}

\subsubsection{Faculties}

All faculties, except that of law took part in the study. Law was omitted because as yet it does not offer postgraduate courses.

\subsubsection{Deans of faculties}

All the deans of the university faculties except law took part in the study. 


\subsubsection{Heads of Department}

All the heads of postgraduate departments in the said faculties automatically took part in the study.

\subsubsection{Post Graduate Students}

Stratified random sampling was used to select the post graduate students who participated in this study. This sampling technique was used because the student's population is heterogeneous. The students were therefore stratified into the following strata namely: sex, programme of study, year of study and modes of study.

\subsection{Description of Data Collection Instruments}

To collect the required information from the informants the following instruments were used:

i) Questionnaires: this is a research instrument consisting of a series of questions and other prompts for the purpose of gathering information from the respondents.

ii) Interview guides: this is a list of questions to be raised during an interview

iii) Focus Group Discussions guides

These three instruments of data collection were used for triangulation purposes. As such, therefore, each of these instruments was expected to enrich and compliment the others and at the same time check on coherence of facts. The questionnaires comprised of both open and closed ended questions that were structured to derive the required information from the respondents. Interview guides were likewise used to gather information about what specific respondents know, think, like and how they perceive certain phenomena (Ogula, 1998). Focus Group Discussion involves a small group of participants under the guidance of the moderator talking about topics of important to the researcher and respondent themselves. This instrument ensures that there are free discussions of the topic (Ogula, 1998). In this study the respondents were placed in groups of five to eight and the researcher acted as the moderator while taking notes and recording their discussions by use of a simple tape recorder.

\subsubsection{Post Graduate Students Questionnaires}

The questionnaire had a cover letter and consisted of five sections: Section A: this sought demographic information of the respondents, while Section $B$ consisted of questions that sought information to answer the first research question namely Factors influencing the respondents desire for post graduate education, Section $\mathrm{C}$ consisted of questions which sought information to the third research question; the factors that post graduate students, looked for when they chose an institution for professional development Section $D$ sought the respondents views on the quality and relevance of programmes offered at CUEA while section $E$ enquired the kind of improvements the respondents desired on various areas such as admissions, quality of the academic programmes, content delivery, fee, facilities and learning modes.

\subsubsection{Interview Guide}

Interview guide was used to collect information from the deans of various faculties Catholic University of Eastern Africa. It sought to obtain data on the criteria for selection of students for post graduate studies and the general administration of the programme as well as the methods that are used to select the courses of study in any programme.

\subsubsection{Piloting}

The questionnaires were piloted in one faculty that did not participate in the study. The purpose for piloting was to ensure that items in the questionnaire are stated clearly and have the same meaning to all respondents.

\subsubsection{Validity}

The instruments for used data collection in this study were given to at least three experts who looked at them independently to ascertain whether they solicited the kind of information they purported to collect. Their views on the 
content and structure were incorporated in the final draft of the instrument.

\subsubsection{Reliability}

Reliability of an instrument is usually expressed as a correlation co-efficient that measures the strength of association between variables. Such co-efficient vary between $(-1.00$ and +1.00$)$ where 0.00 shows there is no reliability while 1.00 shows perfect reliability. The co-efficient assisted the researcher to know the extent to which an instrument was free from error variance which could be caused by factors such as ambiguous questions, language, mood of respondents or researcher's ordered items in the instrument. To test for reliability in this study, test-retest technique was employed. Thus the same instrument was administered twice to the same individuals. The second administration was done one week after the first one. The scores from both tests were correlated to obtain the co-efficient of reliability. Since the co-efficient obtained was 0.5 and above the instrument was considered reliable. According to Mason and Bramble (1997) a coefficient of reliability that is 0.5 and above is acceptable.

\subsection{Ethical Issues}

The ethical issues considered related to voluntary participation and treating the respondent's information confidentiality. The participants in research were informed what the study was all about so as to make their own judgment on whether to participate or not. In this study, the researcher introduced the study and assured the participants of confidentiality of the information provided.

In order to protect the privacy of the participants, confidentiality was guaranteed by assuring them that the information provided would only be used for academic purpose.

\subsection{Description of Data Collection Procedures}

After obtaining permission from the university supervisors, the researcher wrote a letter to the vice chancellor/rector of the Catholic University of Eastern Africa requesting permission to collected data from the sampled faculties. The researcher also requested the rector to write an introduction letter for her so that she can gain access in faculties. The researcher also applied for a permit from the Ministry of Higher Education, Science and Technology. Having done this the researcher then sampled the students who would take part in the study. The researcher explained the purpose of the study to the participants and then requested them to take part in it. Each participant was given a consent form to sign. However, any participant willing to withdraw from the study at any point during the study was free to do so. A captive group was formed ideal for the administration of the questionnaire so that duly filled ones would collect immediately. In cases where that method was not possible, arrangements were made to pick them later. The researcher in person will facilitated the interviews with the participants. The researcher booked appointment with the participants for interviews and focus group discussions. The interviews and focus group discussions were audio recorded.

\subsection{Description of Data Analysis Procedures}

Descriptive and inferential statistics were used to analyze the data that was obtained from the field. Quantitative data from the responses to closed ended type of questions in the questionnaire were coded in the computer by applying the Statistical Package for Social Sciences (SPSS). The results were presented in frequency distributions and percentages. Mean and standard deviations were computed to determine whether the respondents' perceptions on towards the choice of institution for professional development are positive or negative.

Qualitative data collected was analysed following four major steps. In the first stage data processing was done. Here transcriptions of the interviews were done and observed events and actions during the data collection period were transformed into field notes. The second stage involved condensing the data collected. Here, the transcripts were edited and ambiguities removed. Hence, the data categories or themes and sub-categories or sub-themes were identified. In stage three, the data was presented using narratives and direct quotations or verbatim quotes from what the participants said during interviews and focus group discussions. The fourth and final stage was the interpretation of the data based on the findings. 


\section{Presentation And Discussion of the Findings}

\subsection{Introduction}

In this chapter the results of analysis of factors influencing choice of institution for professional development, a case study of postgraduate students' perceptions at the Catholic University of Eastern Africa are presented in tables, graphs and pie charts. The demographic profile of the respondents who participated in the study is presented first. The findings of the study are presented following the research questions. Each research question is dealt with considering different questionnaire items that give relevant data. The summaries of these findings are given in frequency, percentages, crosstabulations, means and standard deviation distributions.

\subsection{Demographic Information of the Respondents}

The demographic information collected about the respondents included; sex, faculty, year of study, mode of learning and programme of study. The rate if return of the research instruments was ninety five percent (95\%). This is because the researcher used captive groups in most faculties.

\subsubsection{Sex of the Respondent}

It was important to collect data regarding the sex of the respondents because if the following reasons; first, it was to ensure the representation of the both the male and female postgraduate students and secondly, it would be used to test whether there is a significant difference in the mean perception scores of the students when categorised by sex. Data regarding the sex of the respondents was therefore collected, analysed and presented in Table 4.1.

Table 4.1: Sex of the Respondents

\begin{tabular}{ccc}
\hline Sex & Frequency & Percentage \\
\hline Female & 65 & 54.2 \\
Male & 55 & 45.8 \\
Total & 120 & 100 \\
\hline
\end{tabular}

It can be observed that $65(54.2 \%)$ of the respondent were female while 55 (45.8\%) were male. These findings suggest that that more female than male students participated in the study. This was probably due to the fact that there are more female students than their male counterparts in some of the departments offering postgraduate studies at the Catholic University of Eastern Africa.

\subsubsection{Faculty of the Respondent}

It was found important to collect data concerning the faculty of the respondents because of the following reasons; first, it was to ensure the representation of all the faculties that offer postgraduate studies. The data collected was analysed in Graph 4.1. 
Graph 4.1: Distribution of the Faculty of the Respondents

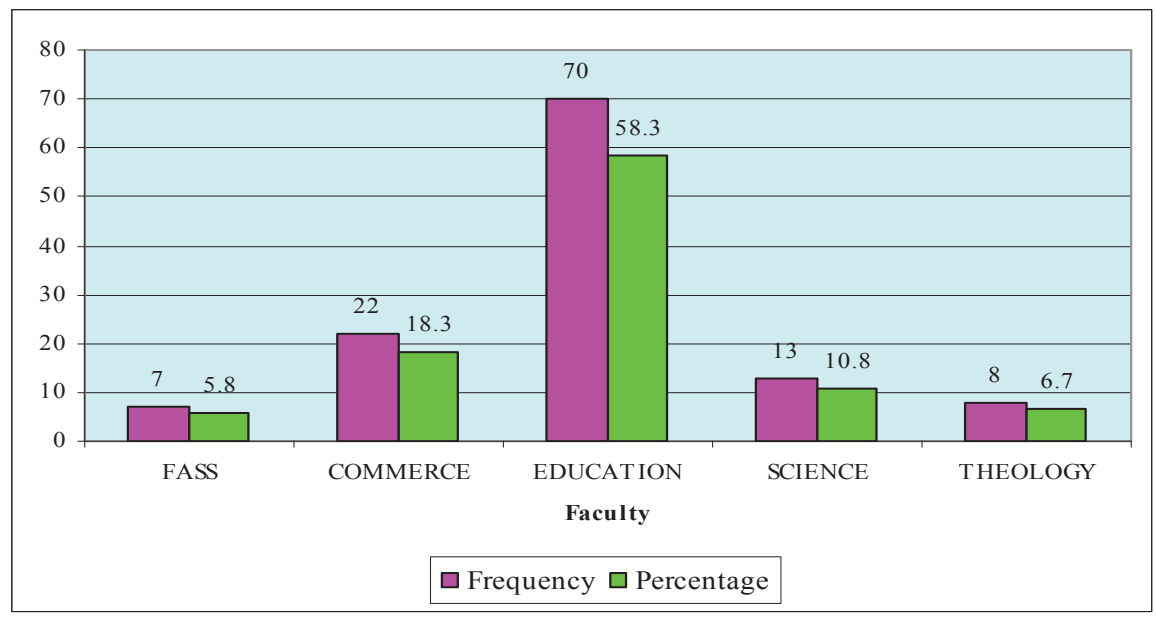

It can be observed that $7(5.8 \%)$ of the respondent were from the faculty of Arts and Social Sciences, 22(18.3\%) were from Commerce, 70(58.3\%) were from Education, 13 (10.8\%) were from Science and 8 (6.7\%) were Theology. These findings suggest that there was high number of students participating in the study from various faculties. This was probably pegged to the fact that there are high enrolments for postgraduate studies in some faculties than others at the Catholic University of Eastern Africa.

\subsubsection{Year of Study of the respondent}

Year of study of the respondent was found important because it would make it possible find out whether students in different years have the same view about the university. The data collected was presented in pie chart 4.1.

Pie Chart 4.1: Distribution of the Year of Study of the Respondents

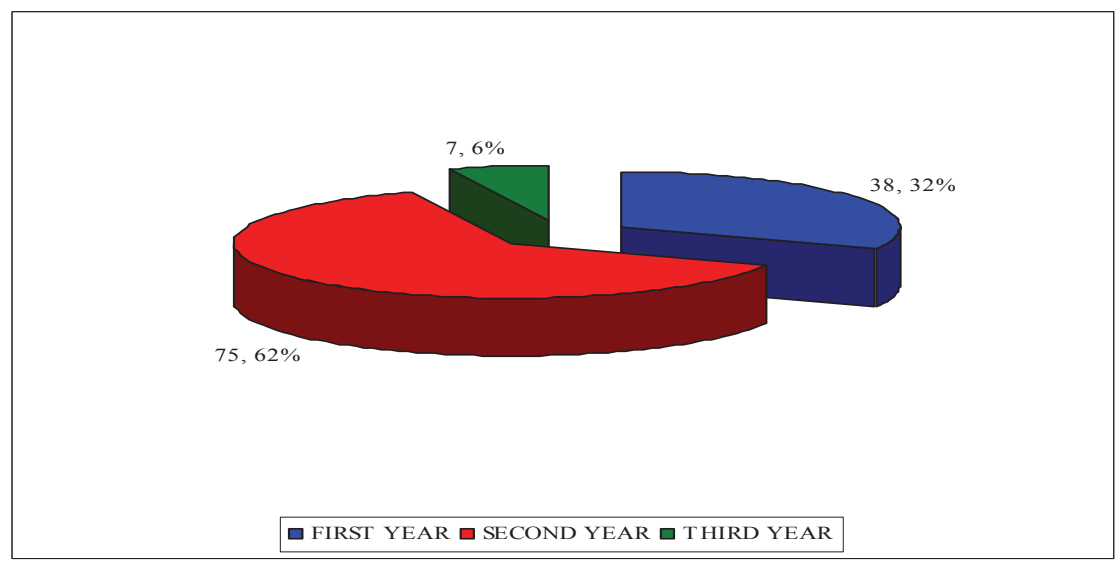

From the pie chart 1.1 it can be seen that $38.32 \%$ of the total respondents were first years, $75.62 \%$ were second years and $7.6 \%$ were third year. 


\subsubsection{Mode of Learning}

The mode of learning of the respondents was found necessary because it would make it possible to compare the perceptions of students in different modes of learning at the Catholic University of Eastern Africa. Data regarding the mode of study was therefore collected, analysed and presented in graph 4.2 .

Graph 4.2: Distribution of the Mode of Learning of the Respondents

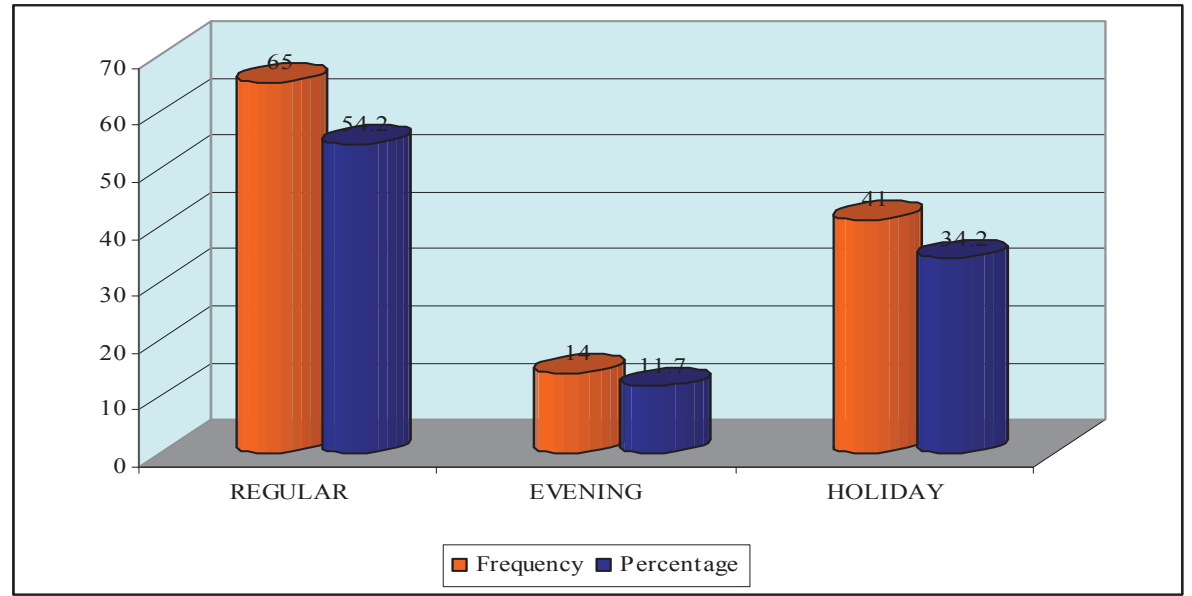

From table 1.2 it is observed that $65(54.2 \%)$ of the total respondents belong to the evening mode, $14(11.7 \%)$ attend the evening mode and $41(34.2 \%)$ are in the Holiday Programme.

\subsubsection{Programme of Study}

It was also found important to know the programme of study the respondents were pursuing that is whether they were Master's or PhD students. Data regarding the programme of study of the respondents was collected, analysed and summarised in pie chart 4.2 .

Pie Chart 4.2: Programme of Study of the Respondents

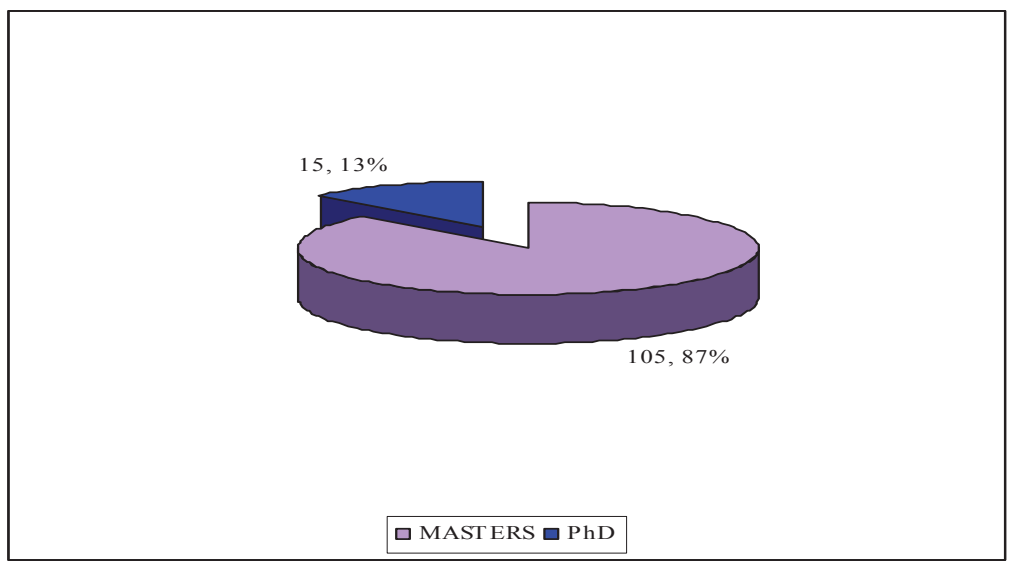


From the table it was found that $105(87.5 \%)$ of the respondents were pursuing masters in various faculties and 15(12.5\%) were PhD students.

\subsection{Factors Influencing Desire for Postgraduate Education}

The first research question sought to find out the factors influencing the desire for postgraduate education, the perceptions of postgraduate students at the Catholic University of Eastern Africa. These factors were categorised under different classifications. The classifications included, competence enhancement, acquisition of relevant skills, promotions, Marketability in the labour market, job retention and security, salary increase, personal growth, to be like peers and friends and finally encouragement by the alumni. Data regarding the factors influencing the desire for postgraduate education was collected from the postgraduate students. It was analysed and summarised in table 4.2.

Table 4.2: Factors Influencing Desire for Postgraduate Education

\begin{tabular}{|c|c|c|c|c|c|c|c|c|c|c|}
\hline \multirow{2}{*}{ Statement } & \multicolumn{2}{|c|}{ SDI } & \multicolumn{2}{|c|}{ WI } & \multicolumn{2}{|c|}{ U } & \multicolumn{2}{|c|}{$\mathrm{FI}$} & \multicolumn{2}{|c|}{ SI } \\
\hline & $F$ & $\%$ & $f$ & $\%$ & $\mathbf{F}$ & $\%$ & $f$ & $\%$ & $F$ & $\%$ \\
\hline For competence enhancement & 9 & 7.5 & 4 & 3.3 & 1 & 0.8 & 12 & 10.0 & 94 & 78.3 \\
\hline To acquire relevant skills & 7 & 5.8 & 5 & 4.2 & 1 & 0.8 & 13 & 10.8 & 94 & 78.3 \\
\hline To facilitate promotion & 9 & 7.5 & 16 & 13.3 & 7 & 5.8 & 38 & 31.7 & 50 & 41.7 \\
\hline Marketability in labour arena & 13 & 10.8 & 6 & 5.0 & 3 & 2.5 & 23 & 19.2 & 75 & 62.5 \\
\hline For job retention & 26 & 21.7 & 19 & 15.8 & 17 & 14.2 & 30 & 25.0 & 28 & 23.3 \\
\hline For salary increase & 21 & 17.5 & 14 & 11.7 & 12 & 10.0 & 29 & 24.2 & 44 & 36.7 \\
\hline Personal growth & 14 & 11.7 & 8 & 6.7 & 0 & 0 & 12 & 10.0 & 86 & 71.7 \\
\hline To be like friends and peers & 54 & 45.0 & 27 & 22.5 & 13 & 10.8 & 13 & 10.8 & 13 & 10.8 \\
\hline Encouragement by the alumni & 40 & 33.3 & 35 & 29.2 & 16 & 13.3 & 21 & 17.5 & 8 & 6.7 \\
\hline
\end{tabular}

It can be observed that when the postgraduate students at CUEA were asked to indicate to what extent the competence enhancement factor influenced their desire for postgraduate education the following information was obtained, 94(78.3\%) of the respondents felt that it strongly influenced, $12(10 \%)$ felt that it fairly influence, $1(0.8 \%)$ was undecided, 4(3.3\%) said that it weakly influenced and 9(7.5\%) felt that it strongly doesn't influence. Majority of the respondents held that one of the main reasons for them to pursue postgraduate studies is for competence enhancement. This finding agrees with the studies carried out by Chivers (2007) on professional development with the aim of determining the ways in which post graduate study in vocational fields supports the development of advanced competence amongst mid-career professionals.

It to can be seen that when the postgraduate students at CUEA were asked to state what extent the factor, acquisition of skills influenced their desire for postgraduate education the following was obtained: $94(78.3 \%)$ said that it strongly influence, 13(10.8\%) said it fairly influenced, 1(0.8\%) were undecided, 5(4.2\%) felt that it weakly influenced and $7(5.8 \%)$ felt that it strongly did not influence. It was clear that many of the respondents enrolled for postgraduate studies in order to acquire relevant skills in their field of specialization. The finding concurs with Hardre (2005) whose study found out that acquisition of skills is important both for their pressing roles as employees and for their ultimate roles in the professoriate. Similarly, it agrees with Malm (2009) who also found out that teacher training programmes need to focus more on objectives such as promoting conflict literacy, self-awareness, understanding; leadership and collaborative skills.

Table 4.2 shows that when the postgraduate students were asked to state the extent to which promotion influenced their desire for postgraduate education, $50(41.7 \%)$ said that it strongly influenced, $38(31.7 \%)$ said it fairly influenced while seven (5.8\%) were undecided. $16(13.3 \%)$ felt that it weakly influenced and $9(7.5 \%)$ felt that it strongly did not influence. The data obtained suggests that promotion is one of the main reasons as to why many of the respondents sought professional development through postgraduate studies.

It to can be observed that when the postgraduate students at CUEA were asked to state what extent the factor, marketability in the labour arena influenced their desire for postgraduate education the following was obtained: $75(62.5 \%)$ said that it strongly influence, 23(19.2\%) said it fairly influenced, 3(2.5\%) were undecided, $6(5.0 \%)$ felt that it weakly influenced and $13(10.8 \%)$ felt that it strongly did not influence. Once again the data suggests that being marketable in the labour market is a factor that made many of the respondents to desire postgraduate education. The findings agree with Malm (2009) who found out that Swedish lecturers' descriptions of what they consider to be competences and qualities 
necessary for future teachers constitute the starting point for a wider discussion on the decisive role of beliefs and emotions in being and becoming a teacher. They also concur with Ronfeldt (2008) who found out that post graduate students negotiate images of themselves as professionals with the images reflected to them by their programmes.

From the table it can be observed how the respondents felt about the factor job retention and security. $28(23.3 \%)$ of the respondents felt that it strongly influenced, 30(25.0\%) said it fairly influenced, 17(14.2\%) were undecided, 19(15.8\%) said that it weakly influences and 26(21.7\%) said it strongly did not influence. The study had considered job retention and security as one of the factors that made the respondents to seek further education, but from the findings of the study there is a number that cannot be ignored said they do not seek professional development for job retention and security. Therefore, the data suggests that this is not a factor.

When asked to comment salary increase the respondents said the following: $44(36.7 \%)$ said it strongly influenced their desire for postgraduate education, 29 (24.2\%) said it fairly influenced, $12(10.0 \%)$ were undecided, 14 (11.7\%) felt it weakly influenced and 21 (17.5\%) said it strongly did not influence. Sixty percent (60\%) of the respondents said that salary increase after completing the programme is a factor that compelled them to seek professional development, hence the findings suggests that salary increase is a factor that the respondent took into account.

As far as personal growth is concerned the respondents said the following; $86(71.7 \%)$ felt that it strongly influenced their desire for postgraduate education, $12(10.0 \%)$ said it fairly influenced, $8(6.7 \%)$ felt it weakly influenced and $14(11.7 \%)$ felt that it strongly did not influence. The findings imply that personal growth is a factor that the respondents considered when seeking professional development.

Table 4.2 gives information on what the respondents felt about the factor on pursuing postgraduate education to be like friends. $13(10.8 \%)$ felt that it strongly influenced, another $13(10.8 \%)$ said it fairly influenced and a further $13(10.8 \%)$ were undecided. $27(22.5 \%)$ felt it weakly influenced and the many 54 (45.0\%) felt it weakly influenced. This suggests that many of the respondents were not pursuing further education to be like their friends but for other reasons.

The study had considered encouragement by the alumni as one of the factors that made the respondents to seek further education. From the table it can be seen that the respondents had the following to say about encouragement by the alumni to go for further studies; $8(6.7 \%)$ said that it strongly influenced, $21(17.5 \%)$ said it fairly influenced, 16 (13.3\%) were undecided, 35 (29.2\%) said it weakly influenced and 40 (33.3\%) felt it strongly did not influence. The findings of the study suggest that majority did not seek professional development because the alumni encouraged them. Therefore, the findings imply that encouragement by the alumni is not a factor.

\subsubsection{Cross-tab of Desire for Postgraduate Studies and Sex}

The data regarding factors influencing desire for postgraduate studies was cross-tabulated to establish how the female and male students responded to the items. The results of the cross-tab are presented in table 4.3.

Table 4.3: Cross-tab of Factors influencing desire for Postgraduate Studies and Sex

\begin{tabular}{lcccccccccc}
\hline \multirow{2}{*}{ Statement } & \multicolumn{2}{c}{ SDI } & \multicolumn{2}{c}{ WI } & \multicolumn{1}{c}{ U } & \multicolumn{3}{c}{ SI } \\
\cline { 2 - 11 } & $\mathbf{F}$ & $\mathbf{M}$ & $\mathbf{F}$ & $\mathbf{M}$ & $\mathbf{F}$ & $\mathbf{M}$ & $\mathbf{F}$ & $\mathbf{M}$ & $\mathbf{F}$ & $\mathbf{M}$ \\
\hline For competence enhancement & 3 & 6 & 1 & 3 & 0 & 1 & 9 & 3 & 52 & 42 \\
To acquire relevant skills & 3 & 4 & 2 & 3 & 0 & 1 & 8 & 5 & 52 & 42 \\
To facilitate promotion & 2 & 7 & 7 & 9 & 2 & 5 & 22 & 16 & 32 & 18 \\
Marketability in labour arena & 6 & 7 & 2 & 4 & 1 & 2 & 13 & 10 & 43 & 32 \\
For job retention & 13 & 13 & 8 & 11 & 12 & 5 & 11 & 19 & 21 & 17 \\
For salary increase & 7 & 14 & 5 & 9 & 6 & 6 & 20 & 9 & 27 & 17 \\
Personal growth & 7 & 7 & 3 & 5 & 5 & 7 & 0 & 0 & 50 & 36 \\
To be like friends and peers & 32 & 22 & 15 & 12 & 7 & 6 & 4 & 9 & 7 & 6 \\
Encouragement by the alumni & 23 & 17 & 19 & 16 & 7 & 9 & 10 & 11 & 6 & 2 \\
\hline
\end{tabular}

The table shows the responses on the various factors that influenced the participants to join the postgraduate studies. For competence enhancement 52 female and 42 male respondents were strongly influenced, nine female and three male were fairly influenced, three female and six male were not strongly influenced, one female and three male were weakly influenced and one male was undecided. 
Fifty two female and forty two male were strongly influenced with the need to acquire relevant skills to join postgraduate studies, eight female and five male were fairly influenced, two female and three male were weakly influenced while three female and four male were not strongly influenced and only one male respondent was undecided as to whether he was influenced or not.

Third two female and 18 male indicated that they have been strongly influenced by the need for promotion to enroll for postgraduate studies, 22 female and 16 male have been fairly influenced, seven female and nine male were weakly influenced and two female and seven male were not strongly influenced.

Forty three female and 32 male enrolled for postgraduate studies because of being influenced by the marketability in the labour arena, 13 female and 10 male were fairly influenced, six female and seven male were strongly not influenced while two female and four male were weakly influenced.

\subsection{Factor that Postgraduate Students look for in their Choice of CUEA}

The second research question sought to establish some of the factors that postgraduate students looked for in the choice of CUEA as their preferred institution for professional development. This information was found useful because it would assist in establishing the percentage of the respondents that had chosen the institution as their first choice and to eventually get to know what factors the considered in doing so. Data regarding whether CUEA was the first choice institution was collected from the students. It was analysed and presented in pie chart 4.3.

Pie Chart 4.3: CUEA as First Choice

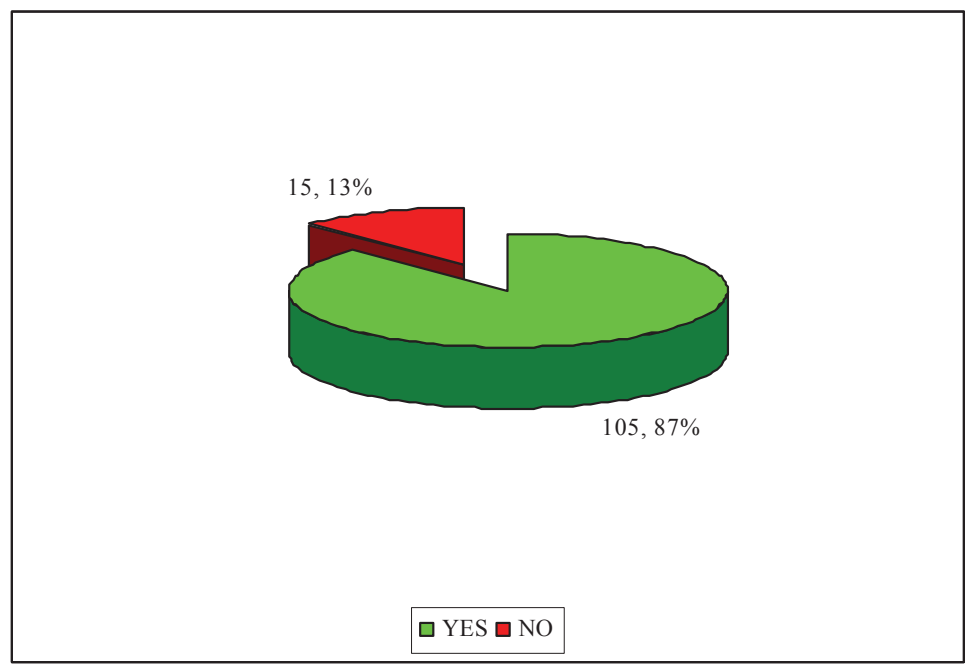

Out of the 120 respondents 105 (87.5) had chosen CUEA as their preferred institution for their postgraduate education while 15 (12.5\%) had not chosen CUEA as their first choice.

Those who said that CUEA was their first choice gave very many reasons ranging from; quality of education, the only university offering their course of choice, students worked hard and owned their work, serious academic staff, completion of the programme within the scheduled time frame, the course work in the PhD programme seemed to be a favourite of many in the programme. Others simply admired the way the institution is run and the culture of hard work among the lecturers and students that is the rapport. The commitment of the lecturers to their work and availability attracted quite a number of the respondents to make CUEA their institution of choice. To some the tuition fee is much lower than other private universities. For others it was the undergraduate experience that made the make CUEA their institution of choice the while others said it is the effectiveness of the teaching that propelled to choose this institution for professional development. 
Lastly, some said that institution has not been associated with malpractices of any kind, students' riots, sure of results and correct marks are the reasons that they made the university their first choice for postgraduate studies.

\subsubsection{Factors considered for choice of CUEA}

It was important in this study to find out some of their factors that attract the respondents to the Catholic University of Eastern Africa. Data collected regarding these factors from the postgraduate students who participated in this study, was analysed and reported as shown in the table 4.4.

Table 4.4: Factors Postgraduate Students looked for in the choice of CUEA

\begin{tabular}{|c|c|c|c|c|c|c|c|c|c|c|}
\hline \multirow{2}{*}{ Statement } & \multicolumn{2}{|c|}{ VR } & \multicolumn{2}{|c|}{$\mathbf{R}$} & \multicolumn{2}{|c|}{ U } & \multicolumn{2}{|c|}{ SR } & \multicolumn{2}{|c|}{ NR } \\
\hline & $F$ & $\%$ & $f$ & $\%$ & $f$ & $\%$ & $f$ & $\%$ & $\mathrm{~F}$ & $\%$ \\
\hline Location of CUEA is convenient & 38 & 31.7 & 29 & 24.2 & 3 & 2.5 & 12 & 10.0 & 38 & 31.7 \\
\hline Programmes are attractive & 73 & 60.8 & 38 & 31.7 & 4 & 3.3 & 4 & 3.3 & 1 & 0.8 \\
\hline CUEA graduates are marketable & 41 & 34.2 & 47 & 39.2 & 20 & 16.7 & 5 & 4.2 & 7 & 5.8 \\
\hline Predictability of course duration & 87 & 72.5 & 26 & 21.7 & 3 & 2.5 & 4 & 3.3 & 0 & 0.0 \\
\hline Quality of degrees offered & 72 & 60.0 & 38 & 31.7 & 7 & 5.8 & 2 & 1.7 & 1 & 0.8 \\
\hline Lecturer/Supervisor availability & 69 & 57.5 & 38 & 31.7 & 8 & 6.7 & 3 & 2.5 & 2 & 1.7 \\
\hline Tuition fee is manageable & 18 & 15.0 & 22 & 18.3 & 16 & 13.3 & 26 & 21.7 & 38 & 31.7 \\
\hline Church affiliation & 30 & 25.0 & 24 & 20.0 & 9 & 7.5 & 20 & 16.7 & 37 & 30.8 \\
\hline Dictates of sponsors & 15 & 12.5 & 10 & 8.3 & 21 & 17.5 & 15 & 12.5 & 59 & 49.2 \\
\hline Favourable class size & 41 & 34.2 & 43 & 35.8 & 10 & 8.3 & 10 & 8.3 & 16 & 13.3 \\
\hline Good resources and facilities & 47 & 39.2 & 45 & 37.5 & 10 & 8.3 & 15 & 12.5 & 3 & 2.5 \\
\hline CUEA undergraduate experience & 38 & 31.7 & 13 & 10.8 & 8 & 6.7 & 8 & 6.7 & 53 & 44.2 \\
\hline International environment & 32 & 26.7 & 32 & 26.7 & 13 & 10.8 & 21 & 17.5 & 22 & 18.3 \\
\hline
\end{tabular}

When asked to give their view on how relevant the factor; location of CUEA is convenient to them in their choice of institution they responded as follows: 38 (31.7\%) said that is very relevant, $29(24.2 \%)$ said that it relevant, three (2.5\%) were undecided, $12(10.0 \%)$ said it is slightly relevant and $38(31.7 \%)$ said it is not relevant. The findings suggest that location of the university is relevant in choosing CUEA as the institution for pursuing postgraduate studies.

The table shows how the respondents felt when asked the relevance of the programmes of offered at CUEA influenced their choice of institution, they said: $73(60.8 \%)$ said it very relevant, $38(31.7 \%)$ felt its relevant, $4(3.3 \%)$ were undecided, $4(3.3 \%)$ said it is slightly relevant and $1(0.8 \%)$ said it is not relevant. This suggests that most of the respondents who participated in the study considered the kind of programmes offered when choosing an institution for professional development. Thus the relevance of programmes is a factor.

From the table it can be observed how the respondents felt about the factor CUEA graduates being marketable, 41 (34.2\%) of the respondents felt that it very relevant, $47(39.2 \%)$ said it is relevant, $20(16.7 \%)$ were undecided, 5 (4.2\%) said that it slightly relevant and $7(5.8 \%)$ said it is not relevant. This suggests that the marketability of the graduates of an institution is taken into account when choosing an institution for professional development.

Asked to say how relevant predictable course duration was to them in choosing an institution $87(72.5 \%)$ of the respondents said it is very relevant, $26(21.7 \%)$ said it is very relevant, three (2.5\%) were undecided, and four (3.3\%) said it is slightly relevant. The data obtained here implies that course duration is on of the major factors that the respondents considered when choosing an institution for professional development.

The quality of degree offered emerged as one of the factors taken into account by the respondents when making a choice on the institution for professional development. This is supported by the data in the table which is as follows; 72 (60.0\%) said it is very relevant, 38 (31.7\%) said it is relevant, seven (5.8\%) were undecided, two (1.7) said it is slightly relevant and one (0.8\%) said it is not relevant. Many of the respondents felt the quality of degrees offered in an institution is a factor that they took into account when they chose CUEA as their preferred institution for professional development as implied by the findings.

The table gives information on what the respondents felt when it came to the availability of lecturers as a factor when choosing an institution for professional development. They responded as follows: 69 (57.5\%) said it is very relevant, $38(31.7 \%)$ said it is relevant, eight (6.7\%) were undecided, three (2.5\%) said it is slightly relevant and two (1.7\%) said it 
is not relevant. This suggests that many of the respondents chose CUEA because the lecturers/supervisors are available to the students to assist and guide them in their work and studies.

Tuition fee is yet another factor that the study sort out to find out how it influences the choice of institution for professional development and the respondents responded as indicated in the table, that is, $18(15.0)$ said it is very relevant, 22 (18.3\%) said it is relevant, 16 (13.3\%) were undecided, $26(21.7 \%)$ said slightly relevant and $38(31.7 \%)$ said it is not relevant. The data implies that tuition fee was not a relevant factor for the respondents when they chose CUEA as their preferred institution.

CUEA is an institution affiliated to the Catholic Church, when the respondents were asked how relevant this was to their choosing of this institution for their professional development they responded as follows: $30(25.0 \%)$ said it is very relevant, 24 (20.0\%) felt it is relevant, nine (7.5\%) were undecided, 20 (16.7\%) said it is slightly relevant and 37 (30.8\%) said it is not relevant. The data shows that half the respondents chose this institution because of its affiliation to the church while for the other half the church affiliation was not a key factor.

Sometimes people attend certain institutions because their parents, sponsors or employers insist that they attend those particular institutions. The study wanted to find out whether this is the case with the respondents who participated. Their responses were; $15(12.5 \%)$ said it is very relevant, $10(8.3 \%)$ said it is relevant, 21 (17.5\%) were undecided, 15 (12.5\%) said it is slightly relevant and $59(49.2 \%)$ said it is nor relevant. Thus the data suggests that the dictates of the parents/sponsors/employers does not so much influence the choice of institution. This can be attributed to the fact that many of the postgraduate students are self sponsored.

The study sought to find out what the respondent thought about the class size at CUEA when it comes to picking an institution for professional development. Their responses were as tabulated in the table: $41(34.2 \%)$ said it is very relevant, $43(35.8 \%)$ said it is relevant, $10(8.3 \%)$ were undecided, $10(8.3 \%)$ said it is strongly relevant and $16(13.3 \%)$ said it is not relevant. Their responses imply that the small class sizes at CUEA made many of the respondents to make it their institution of choice.

When asked to give their views on how pertinent the availability of resources and facilities was to their choice of institution their responses were, $47(39.2 \%)$ said it is very relevant, $45(37.5 \%)$ said it is relevant, $10(8.3 \%)$ were undecided, $15(12.5 \%)$ said it is slightly relevant and three (2.5\%) said it is not relevant. The data suggests that many of the respondents chose this institution because of the resources and facilities available at the institution.

The table gives information on what the respondents felt about the factor, undergraduate experience at CUEA being relevant to their choosing the institution for postgraduate professional development, they responded as follows: 38 $(31.7 \%)$ felt that it very relevant, $13(10.8 \%)$ said it relevant, eight (6.7\%) were undecided, eight (6.7\%) felt it is slightly relevant and the $53(44.2 \%)$ felt it is not relevant.

Asked to state the relevance of the multicultural/multinational environment at CUEA, $32(26.7 \%)$ of the respondents felt it was very relevant, $32(26.7 \%)$ others said it was relevant, $13(10.8 \%)$ were undecided, $21(17.5 \%)$ felt it was slightly relevant and 22 (18.3\%) said it was not relevant.

\subsection{Quality and Relevance of Academic Courses Covered in Postgraduate Studies}

The third research question sought to find out what the respondents thought about the relevance and quality of the academic programmes offered at the Catholic University of Eastern Africa. Data regarding the quality and relevance of the CUEA programmes was collected, analysed and presented in table 4.5 .

Table 4.5: Quality and Relevance of the CUEA Programmes

\begin{tabular}{lcccccccccc}
\hline & \multicolumn{3}{c}{ VP } & \multicolumn{3}{c}{ A } & \multicolumn{1}{c}{ G } & \multicolumn{3}{c}{ VG } \\
\cline { 2 - 10 } & $\mathbf{F}$ & $\%$ & $\mathbf{f}$ & $\%$ & $\mathbf{F}$ & $\%$ & $\mathbf{f}$ & $\%$ & $\mathbf{F}$ & $\%$ \\
\hline Quality of the programmes & 2 & 1.7 & 8 & 6.7 & 1 & 0.8 & 42 & 35.0 & 67 & 55.8 \\
Relevance of the programmes & 4 & 3.3 & 7 & 5.8 & 3 & 2.5 & 36 & 30.0 & 70 & 58.3 \\
\hline
\end{tabular}

From the data it can be seen that more than ninety per cent of (90\%) the respondents felt that the academic programmes covered in postgraduate at CUEA are of quality relevant. This is shown by the responses the offered when asked to give their opinion quality of programmes. The data obtained is as follows: 67 (55.8\%) said the quality is very good, 42 (35.0\%) 
said it is good, one (0.8\%) was undecided, $8(6.7 \%)$ said it is average and $(21.7 \%)$ said it is very poor. The data suggests that students are satisfied with the quality of the programmes offered at CUEA.

Regarding the relevance of the programmes offered at CUEA in meeting their needs, the respondents gave their opinion as follows, 70 (58.3\%) said that it is very good, $36(30.0 \%)$ said it is good, three (2.5\%) were undecided, seven $(5.8 \%)$ said it average and four (3.3\%) said it is very poor. Once again it suggests that the respondents felt that the programmes offered at CUEA are relevant to them.

When asked to comment on ways in which they expected the postgraduate programme they were pursuing at CUEA to make them more competitive in the labour market the respondents had a variety of arguments to put across. Some felt the studies would enhance in acquisition of many skills which are relevant to their careers. They also felt that it is an opportunity for them to have many avenues open for them for upward mobility in the cooperate ladder. With the competitive labour market the studies would give them better bargaining power. This means that they would be in a position to ask for better packages and terms of service. They did say that the education offered at CUEA would empower the human resources the capacity and would inculcate professionalism and competence since it all inclusive. Some did feel it is the best route to teaching in institutions of higher learning thus it would facilitate their personal growth and interest in the best way.

The respondents said that the institution would equip them with skills that would enable them to be efficient and prudent in the management of resources and evaluating projects that benefit the community. The work ethics inculcate in the students of CUEA would of good use since they would be able to give what is rightfully belong to the society. The institution encourages hard work and team work among the students and collegiality is witnessed among the lecturers which the students are challenged to emulate. Some of the courses covered in the programme broaden the students' perceptions to reality and make them sensitive to other people's plight in the community. To others it is the knowledge to be able to adequately plan the social activities before implementing them that the university would give them.

\subsection{Suggestions for Improvement}

It was viewed important to find out from the respondents what their suggestions for improvement of certain sectors of the running of the university were. Data regarding the suggestions for improvement were collected, analysed and presented as follows.

\subsubsection{Admissions}

The respondents said that the admissions should be service oriented and not money oriented. The decentralization of registration to the faculties was suggested as this would ease the congestion at the registry. They felt that the personnel at the registry needed to be increased in number for faster and efficient service provision especially when it comes to registration and issuing of transcripts. The personnel at the registry is said to be slow in providing service and thus needs to step up. Suggestions for the separation of different modes of learning/ programmes in admission should be considered to facilitate faster registration. The university should consider digitalizing the operations at the registry, make admissions on-line and do website advertisements as well as involving the media. Computer skills should be made compulsory for every student to enhance communication via internet.

\subsubsection{Quality of Academic Programmes}

The respondent said there is need for researches carried out in the university should be improved to give the institution a better name. The postgraduate duration should be reduced from three years to two. The institution should create linkages with industries and various organizations in order to guarantee internship for the students to gain work experience. Some of the respondent said that there should be increases student-lecturer contact hours to facilitate better interaction between them and for the benefit of the students. Others said that the university should employ their own lecturers to minimize the dependent of the part-time lecturers in the some courses and units. The over reliance of the part-time lecturers may compromise on the quality of work output. There is need to tailor made courses to suit the African continent more so the AMECEA countries. Set committees for the purpose of regular review of the programmes to keep the high standards of the programmes. 


\subsubsection{Delivery of Content}

Some lecturers do no prepare adequately for the classes and they should embrace ICT as much as possible e.g. the use of power point presentations, overhead projectors and smart boards. This would make the lectures more interesting, faster and resourceful. Some of the respondents said that manuals/module should be provided however others felt more lecture and discussions should be encouraged in place of the modules/ manuals. Similarly recognition of the outstanding lectures and students should be put in place, and they should be given incentives to motivate more. There is need for performance appraisal for the lecturers; this would enable them to keep abreast with the dynamism of education. The current library does not have enough books thus it sometimes becomes very difficult to write term papers and research assignments. The content should be evaluated regularly by both lecturers and students.

\subsubsection{Tuition Fee}

Many of the respondents said that the tuition fee is quite high for ordinary citizen thus it locks out the poor but bright students hence the university should consider bursary and scholarships for such students. One of the deans interviewed said, "CUEA is the cheapest among the private universities. In fact, CUEA is the option for the poor".

The dean also said that once a student is admitted to the university he/she enters into a fee contract with the university that does not change till the student graduates. To enable the students who are struggling with fees not miss out on the classes the university should allow payment in instalments. They also said since the whole world is going ICT then the charges on ICT should be done away with. Some of the respondents who are not on the regular should not be charged activity fee since they do not participate in games, trips and the general co-curricular activities at the university.

\subsubsection{Facilities and Resources}

Most of the respondents who participated in the study said that the facilities at the university are good; however a substantial number of them said that books are either unavailable or inadequate. The standards of the facilities at the institution is good but needs to be maintained, for example the classes are usually very dusty and the washrooms are not kept clean. Electronic borrowing cards in the library and computer rooms should increased within the university to enable students to access internet easily.

Recreational facilities are limited at the campus thus addition would make possible to have a variety. They also said that the photocopy services are limited forcing students to spend sometime looking for this service therefore it is necessary to increase these services.

\subsubsection{Modes of Learning}

To some of the respondents the three modes, that is the regular, the evening and the holiday programme are satisfactory however some of them felt that the holiday programme should be extended to $f$ tour weeks. The university needs to introduce distance learning as well as e-learning programmes. The lecturers and head of departments should have frequent meetings to evaluate the teaching learning process at the university.

Many of the respondents said that they would like to sees the Christian values more so the Catholic values upheld at the university since it is a catholic institution. The lecturers should be encouraged to uphold the religious and moral values. They also felt it is important to establish exchange programmes with other universities.

\subsection{Hypotheses Testing}

\subsubsection{Relationship between Desire for Postgraduate Studies and Selected Demographic Characteristics}

The fourth research question generated two hypotheses, one on mean desire for postgraduate studies scores of students when categorised by sex and another when categorised by faculty. To test the hypotheses, and to decide whether to reject or not reject the null hypotheses, the researcher used the t-test of independence applying SPSS version 11.5 at a 0.05 level of significance in determining the mean desire for postgraduate studies and mean choice of CUEA scores of students when categorised by sex and ANOVA at the same significance level when categorised by faculty. The decision 
rule was reached by interpreting the $p$-value. When $P<0.05$ it means there is evidence against the null hypothesis. Hence, reject it and when $\mathrm{P}>0.05$ there is no evidence against the null hypothesis. Hence, do not reject the null hypothesis.

\subsubsection{INTERPRETING a (p-value)}

$\mathrm{P} \leq 0.001 \quad$ there is very strong evidence against the null hypothesis

$0.001<P \leq 0.01 \quad$ there is strong evidence against the null hypothesis

$0.01<P \leq 0.05 \quad$ there is some evidence against the null hypothesis

$P>0.05 \quad$ there is no evidence against the null hypothesis

\subsubsection{Relationship between Desire for Postgraduate Studies and Sex}

Ho There is no significant difference in the mean desire for postgraduate studies score of students when categorised by sex.

Ha There is a significant difference in the mean desire for postgraduate studies score of students when categorised by sex.

Table 4.6: Group Statistics for Desire for Postgraduate Studies

\begin{tabular}{cccc}
\hline SEX & N & Mean & Std. Deviation \\
\hline FEMALE & 65 & 33.58 & 6.220 \\
MALE & 55 & 31.13 & 6.441 \\
\hline
\end{tabular}

The group statistics for the data shows that there 65 female and 55 male students who participated in the study. The mean for the female was 33.58 and their standard deviation 6.22 while the mean for the male was 31.13 and their standard deviation 6.441. To find out the difference between the two means a t-test was conducted.

Table 4.7: Mean Desire for Postgraduate Studies of Students when Categorised by Sex

\begin{tabular}{|c|c|c|c|c|c|c|c|}
\hline & \multicolumn{2}{|c|}{$\begin{array}{c}\text { Levene's Test for Equalit) } \\
\text { of Variances }\end{array}$} & \multicolumn{5}{|c|}{ t-test for Equality of Means } \\
\hline & $\mathrm{F}$ & Sig. & $\mathrm{t}$ & df & $\begin{array}{l}\text { Sig. (2- } \\
\text { tailed) }\end{array}$ & $\begin{array}{c}\text { Mean } \\
\text { Difference }\end{array}$ & $\begin{array}{l}\text { Std. Error } \\
\text { Difference }\end{array}$ \\
\hline $\begin{array}{l}\text { Equal variances } \\
\text { assumed }\end{array}$ & 1.189 & .278 & 2.122 & 118 & .036 & 2.46 & 1.158 \\
\hline $\begin{array}{l}\text { Equal variances not } \\
\text { assumed }\end{array}$ & & & 2.115 & 113.313 & .037 & 2.46 & 1.162 \\
\hline
\end{tabular}

According to the result in table 4.7, the (p-value) for the levene's test for equality of variances indicated is 0.278 which is greater than 0.05 . What this finding implies is that equal variances were assumed in this test. The $\mathrm{p}$-value for the t-test for equality of means in this test is 0.037 . Therefore, there is a significant difference in the mean desire for postgraduate studies score of students when categorised by sex. This finding implies that the factors that the male consider when joining postgraduate studies are different from those their female counterparts consider. It concurs with Ackah and Heaton (2004) who found out that there is a growing similarity in male and female careers but very different perceptions regarding factors influencing career paths and career progression. However, Ackah and Heaton's study did not test a hypothesis which the current study has done. It would therefore have been impossible to make such an inference.

\subsubsection{Relationship between Desire for Postgraduate Studies and Faculty}

Ho There is no significant difference in the mean desire for postgraduate studies scores of students when categorised by faculty. 
Ha There is a significant difference in the mean desire for postgraduate studies scores of students when categorised by faculty.

Table 4.8: Mean Desire for Postgraduate Studies of students when Categorised by Faculty

\begin{tabular}{lccccc}
\hline & Sum of Squares & $\mathrm{df}$ & Mean Square & $\mathrm{F}$ & Sig. \\
\hline Between Groups & 692.428 & 4 & 173.107 & 4.736 & .001 \\
Within Groups & 4203.363 & 115 & 36.551 & & \\
Total & 4895.792 & 119 & & & \\
\hline
\end{tabular}

According to the result in table 4.8, the (p-value) indicated is 0.001 which is less than 0.05 . Therefore, there is a significant difference in the mean desire for postgraduate studies score of students when categorised by faculty. This implies that students of different faculties consider joining postgraduate studies for different factors. This means that postgraduate students in the faculty of education for example considered different factors when joining graduate studies than their counterparts in other faculties. This is a rather interesting finding. However, we did not come across any study that either supports or contradicts this finding.

\subsubsection{Relationship between Choice of CUEA and Selected Demographic Characteristics}

The fifth research question generated two hypotheses, one on mean choice of CUEA scores of students when categorised by sex and the other when categorised by faculty. Similarly, to test the hypotheses, and to decide whether to reject or not reject the null hypotheses, the researcher used the t-test of independence applying SPSS version 11.5 at a 0.05 level of significance in determining the mean desire for postgraduate studies and mean choice of CUEA scores of students when categorised by sex and ANOVA at the same significance level when categorised by faculty. The decision rule was reached by interpreting the $p$-value.

\subsubsection{Relationship between Choice of CUEA and Sex}

Ho There is no significant difference in the mean choice of CUEA score of students when categorised by sex.

$\mathrm{Ha}$ There is a significant difference in the mean choice of CUEA score of students when categorised by sex.

Table 4.9: Group Statistics for Choice of CUEA

\begin{tabular}{cccc}
\hline SEX & N & Mean & Std. Deviation \\
\hline FEMALE & 65 & 30.89 & 6.551 \\
MALE & 55 & 32.07 & 7.264 \\
\hline
\end{tabular}

The group statistics for the data shows that there 65 female and 55 male students who participated in the study. The mean for the female was 30.89 and their standard deviation 6.551 while the mean for the male was 32.07 and their standard deviation 7.264. To find out the difference between the two means a t-test was conducted.

Table 4.10: Mean Choice of CUEA Scores of Students when Categorised by Sex

\begin{tabular}{|c|c|c|c|c|c|c|c|}
\hline & \multicolumn{2}{|c|}{$\begin{array}{c}\text { Levene's Test for } \\
\text { Equality of Variances }\end{array}$} & \multicolumn{5}{|c|}{ t-test for Equality of Means } \\
\hline & $\mathrm{F}$ & Sig. & $t$ & df & $\begin{array}{l}\text { Sig. (2- } \\
\text { tailed) }\end{array}$ & Mean Difference & $\begin{array}{l}\text { Std. Error } \\
\text { Difference }\end{array}$ \\
\hline $\begin{array}{l}\text { Equal variances } \\
\text { assumed }\end{array}$ & .460 & .499 & -.936 & 118 & .351 & -1.18 & 1.262 \\
\hline $\begin{array}{l}\text { Equal variances } \\
\text { not assumed }\end{array}$ & & & -.928 & 109.952 & .356 & -1.18 & 1.273 \\
\hline
\end{tabular}


According to the result in table 4.10 , the (p-value) for the levene's test for equality of variances indicated is 0.499 which is greater than 0.05 . What this finding implies is that equal variances were assumed in this test. The $p$-value for the t-test for equality of means in this test is $\mathbf{0 . 3 5 6}$. Therefore, there is no significant difference in the mean choice of CUEA scores of students when categorised by sex. This means that sex of the respondent does not influence the choice of CUEA as the institution where one would seek to pursue postgraduate studies. In our literature search, we did not come across a study that supports or contradicts this finding.

\subsubsection{Relationship between Choice of CUEA and Faculty}

Ho There is no significant difference in the mean choice of CUEA scores of students when categorised by faculty.

Ha There is a significant difference in the mean choice of CUEA scores of students when categorised by faculty.

Table 4.11: Mean Choice of CUEA Score of students when Categorised by Faculty

\begin{tabular}{lccccc}
\hline & Sum of Squares & df & Mean Square & F & Sig. \\
\hline Between Groups & 71.998 & 4 & 18.000 & .372 & .828 \\
Within Groups & 5565.469 & 115 & 48.395 & & \\
Total & 5637.467 & 119 & & & \\
\hline
\end{tabular}

According to the result in table 4.11 , the (p-value) indicated is 0.828 which is less than 0.05 . Therefore, there is no significant difference in the mean choice of CUEA scores of students when categorised by faculty. This means that the faculty of the respondent does not influence the choice of CUEA as an institution for pursuing postgraduate studies. Sax and Bryant (2006) on their part found out that aspects of the college environment, including the peer culture, faculty interaction, and curriculum, all contribute to shifts to or from non traditional career choices. However, there is no mention on whether these factors also contribute to the choice of institution.

\subsection{Conclusion}

This chapter has presented and discussed the findings of the study. In particular the various factors that influence the search for postgraduate education as well as those that influence the choice of preferred institution, in the case the Catholic University of Eastern Africa, among graduate students have been highlighted. The study findings concur with the postulates of the theoretical framework, conceptual framework and the literature review in regard to the factors that influence the desire for professional development through postgraduate education. These factors include competence enhancement, acquisition of relevant knowledge and skills, to facilitate promotion, to ensure marketability in the labour market, job retention, salary increment, personal growth, self-actualization and the desire to be like one's peers.

In regard to the preference for CUEA among postgraduate students several factors were deduced. These include convenience of its location, attractiveness of academic programmes offered, marketability of the programmes, predictability of course duration, high quality of degrees offered and availability of lecturers and supervisors. Other factors are favourable class sizes, availability of good learning resources and facilities, good undergraduate experience at CUEA, the international environment at CUEA, manageability of tuition fee, church affiliation and dictate of sponsors.

It was, however, interesting to note that there was a significant difference between the reasons that motivated male postgraduate students and their female counterparts to seek postgraduate education. For instance, whereas male students were motivated by the desire for personal growth, search for self-actualization and the desire to be like their peers, their female counterparts were driven by the desire for upward mobility, salary increment and job retention. The reasons underlying these variations can be a subject of investigation for another study. The next chapter will discuss the summary, conclusions and the recommendations of the study.

\section{Summary, Conclusions and Recommendations}

\subsection{Introduction}

In chapter four of this study, analysis of the findings was presented. This chapter presents a summary of the research 
findings. It then gives conclusions derived from the study and makes recommendations.

The purpose of this study was to analyse the factors influencing choice of institution for professional development, a case study of postgraduate students' perceptions at the Catholic University of Eastern Africa. The study began by giving a justification for lifelong learning and professional development. It was pointed out that lifelong education maintains the professionals' currency, fulfilment as individual citizens and provides an internationally competitive work force and enrichment of society. Hence, one central purpose of continuing professional education is to bring practicing professionals in contact with new knowledge and ideas. It also gave a brief synopsis of the Catholic University of Eastern Africa.

Theoretical as well as empirical related literature was reviewed. Data was collected through a questionnaire and interviews. The respondents to the questionnaire were the postgraduate students in various faculties at the Catholic University of Eastern Africa and the interviewees were faculty deans. The results were presented in accordance with the research questions and hypotheses stated in chapter one using frequency distribution and percentages in tables and charts. Finally, the t-test was used to establish whether there is a significant relationship between desire for postgraduate studies as well as choice of CUEA and sex of the respondent. Similarly, ANOVA was used to establish whether there is a significant relationship between desire for postgraduate studies as well as choice of CUEA and faculty of the respondent. The hypotheses in the study were tested at a 0.05 level of significance.

\subsection{Summary of Findings}

Findings according to factors influencing postgraduate students to pursue lifelong education were competence enhancement, acquisition relevant skills in the fields of specialization, promotion to next grade at the work place, enhancement of ones marketability, salary increment and personal growth. However, job retention and security, peer influence and encouragement from the alumni are not factors influencing the desire for studies.

Findings according to factors determining one's choice of institution for postgraduate education in view of professional development were location of the university, programmes offered, marketability of the graduates, course duration, quality of degrees, availability of lecturers and supervisors, church affiliation, small class sizes at CUEA as well as resources and facilities available at the institution. However, tuition fees and parents, sponsors or employers did not influence the students to choose CUEA.

Findings according to perceptions of postgraduate students of Catholic University of Eastern Africa on the quality of educational programmes good and that the programmes were relevant to their respective professions.

It was also found out that sex and faculty of the respondent affect desire for postgraduate studies while they do not affect choice of CUEA at a 0.05 level of significance.

\subsection{Conclusions}

Based on the findings of this study, several conclusions were made.

Male students were motivated by the desire for personal growth, search for self-actualization and the desire to be like their peers while their female counterparts were driven by the desire for upward mobility, salary increment and job retention to pursue postgraduate studies.

These factors that students consider to choose the institution where they pursue postgraduate studies include convenience of its location, attractiveness of academic programmes offered, marketability of the programmes, predictability of course duration, high quality of programmes offered and availability of lecturers and supervisors.

There is a significant difference in the mean desire for postgraduate studies score of students when categorised by sex. faculty.

There is a significant difference in the mean desire for postgraduate studies score of students when categorised by

There is no significant difference in the mean choice of CUEA scores of students when categorised by sex. by faculty.

There is no significant difference in the mean desire for postgraduate studies score of students when categorised 


\subsection{Recommendations}

Based on the conclusions of this study, the following recommendations were made. One, attractiveness of the academic programmes offered by the university were pointed out is a factor that students considered when choosing the institution when they wish to pursue postgraduate studies. The Catholic University of Eastern Africa should therefore ensure that the programmes offered are relevant and attractive so that many more students may choose this institution for professional development. This can be done by involving all the stakeholders including employers in the planning and designing of the curriculum.

Two, predictability of the course duration is yet another factor that attracts students to CUEA. This good practice should therefore be maintained by ensuring that students complete their courses within the duration stipulated by ensuring that students are assigned committed supervisors to supervise their thesis and dissertations in good time.

Three, another factor that students consider is the quality of programmes offered. The university must therefore ensure that the quality of the programmes is maintained by reviewing the programmes constantly to meet the needs and interests of the world. lecturers should prepare adequately for the classes and they should embrace ICT as much as possible. For instance the use of power point presentations, overhead projectors and smart boards should be enhanced in line with the current global learning/teaching trends. This requires training. The university should therefore facilitate the training through workshops and seminars.

Four, it also emerged from the data that the process of admission is cumbersome and characterised by long queues at the registry and accounts sections, lack of examinations results and wrong fee balances for the students. This situation has been caused by the teething effects of the introduction of ICT. It would be appropriate to implement the new system in phases so that for a period it works concurrently with the old system and eventually phase out the old one. For instance, the university should encourage on-line registration, fees payment and examination results verification. This augurs well for customer care delivery and service.

Five, the location of the university is also a factor that students consider when choosing an institution for professional development. The study therefore recommends that the university considers the possibility of investing on students' accommodations in its strategic plans. This would make it more convenient for students from distant locations such as those from remote areas and foreign countries.

\section{References}

Abasov, Z. A. (2007). Russian Education \& Society, Vol.49 n3 p23-34

Anderson, A. \& Marshall, V. (1994) Core versus occupational-specific skills (Horsham, The Host Consultancy, Labour Market Intelligence Unit).

Banilower, E. R., Heck, D.J., Weiss, I. R. (2008) Journal of Research in Science Teaching, vol 44 n3 p375-395

Becker, G.S. (1964) Human Capital. New York. Colombia University press

Blustein, D, L. (2006). The Psychology of Working. A New Perspective for Career Development, Counselling and Policy. Mahwah, NJ: Lawrence Erlbaum Associates

Boshuizen, H. P. A. (2004) Does practice make perfect? A slow and Discontinuous process, in: H. P. A. Boshuizen, R. Bromme \& H. Gruber (Eds)

Chivers, G. (2007).Journal of European Industrial Training, Vol.31 n8 p639-659

Collins, A. \& Watts, A. G. (1996). The Death of Transfiguration of Career and Career Guidance? British journal of Guidance and Counseling 24(3), 384-398.

Eruat, M. (2006). Developing professional knowledge and competence Routledge Falme, Taylor and Francis Inc, 270 Madison Avenue NY 10016.

Hardre, P. L. (2005). Innovative Higher Education, Vol. 30 n3 p163-175 Sep 2005. 13 pp. (Peer Reviewed Journal)

Jones, N., Fear, N. (1994), Continuing professional development; perspectives from human resource professionals", Personnel Review, vol.23 No.8, pp.49-60

John, W. Best and James, V. Khan (2003), Research in Education. Prentice Hall of India, Private Limited

Kaufman, R., Thiagarajan, S., and MacGillis, P. (1997). Introduction: The changing realitites of human and organizational performance improvement. In R. Kaufman, S. Thiagarajan, and P. MacGillis (Eds.), The guidebook for performance improvement. San Francisco: Jossey-Bass/Pfeiffer.

Madden, C.A., Mitchell, C.A. (1993), "Professional, Standards and Competence: a Study for the Continuing Education for the Professionals", University of Bristol, Bristol.

Malm, B. (2009). Journal of Education for Teaching: International Research and Pedagogy, v35 n1 p77-91 Feb 2009 15pp

Mason, J.E. and Bramble, W. J. (1997), Research in Education and the Behavioral Science. USA: Brown and Benchmark. 
Mcliveen, P. (2007). Career Development and the Skills Shortage: A Lesson from Charles Dickens. Australian Journal of Career Development, 16(1), 13-19.

Mugenda, O. M. \& Mugenda, A.G. (1999). Research Methods: Quantitative and Qualitative Approaches. Nairobi: African Centre for Technology Studies (ACTS) press.

Nachmias,C.F \& Nachmias,D. (1996). Research Methods in social sciences (5th Ed) London: Arnold

Professional learning: gaps and transitions on the way from novice to expert, Dordrecht Kluvert Academic Publishers.

Paulson, K. (2001) Using competencies to connect the workplace and Post secondary education, New Directions for Institutional Research, 110, 41-54.

Ronfeldt, M. Grossman, P. (2008). Teacher Education Quarterly, v35 n3 p41-60 Sum 2008. 20 pp. (Peer Reviewed Journal)

Schultz, Theodero (1960) Capital Formation by Education. The Journal of Political Economy vol 68 (6) 571-583

(1973) The Value of the Ability to Deal with Disequilibria. A Journal of Economic Literature 13(3) 822-846

Sibbel, A. (2009). International Journal of Sustainability in Higher Education, v10 n1 p68-82 2009. 15 pp. (Peer Reviewed Journal)

William, C. (2006), Mind How You Grow, People Management, Vol. 12 issue 13p.53-53 
